\title{
Regional fluctuations and national cohesion in the EU12: a pre-Maastricht assessment*
}

\author{
Francesca Marino ${ }^{\dagger}$ \\ University of Bari (Italy) \\ This version: August 2013
}

\begin{abstract}
This work studies regional fluctuations in the EU12 focusing on regional Gross Domestic Product (GDP) and Employment dynamics over the period 1977-95. The econometric framework is a combination of the Structural Dynamic Factor Model by Forni and Reichlin (1998) and the Dynamic Factor Model by Forni and Reichlin (2001), where each regional variable is decomposed into three orthogonal components, driven by European, national and local shocks. Here we assess the relative importance of the common shocks and provide a first attempt to identify the nature of the common drivers across regions in Europe. According to the model, regions are more synchronized in terms of GDP than in terms of Employment dynamics, and the most cohesive part of Europe does not include all the Old-Europe regions. The possibility of within-country dichotomous behaviours supports a two-level European integration policy, that both fosters the integration process of the less synchronized countries and promotes policies aimed to reduce actual and potential inner dichotomies in high-integrated ones.
\end{abstract}

JEL classification: C13, C32, E32

Keywords: regional co-movements, structural Dynamic Factor Models, European integration

\section{Introduction}

The emergence of region-specific dynamics within countries forming a common currency area is considered by far a serious threat to the optimality of such extreme integration

\footnotetext{
${ }^{*}$ This paper benefited from the comments of the participants at the Fourth Carlo Giannini phD workshop in Econometrics, the 2011 Rimini's Time Series workshop and the 2011 Berlin's Macroeconometrics workshop. I kindly thank Gianni Amisano, Marek Jarociński, Laura Serlenga and Ulrich Woitek for their useful comments and suggestions to previous versions of this paper.

${ }^{\dagger}$ francesca.marino@uniba.it
} 
policies. Indeed, when economic integration of a set of countries fosters regional agglomeration of industrial activities, region-specific shocks are more likely to arise, increasing the probability of asymmetric dynamics and diverging business cycles (Krugman, 1993). At the same time, if a monetary union is formed by regional economies, rather than countries, giving up one's national monetary policy requires that regional fluctuations are in line with the aggregate cycle, since a central bank cannot target idiosyncratic variance (Forni and Reichlin, 2001). This means that monitoring regional dynamics matters both when assessing the efficiency of a monetary union ex ante, and when studying its evolutions ex post, as witnessed by the interest of the European institutions on regional convergence. As stated in the EU Treaty, economic growth should be balanced with economic and social cohesion, implying a careful consideration of regional disparities. Since national dynamics may well conceal marked within-country differences, specific redistribution policies should be implemented in order to preserve inner cohesion.

Despite the relevance of monitoring regional dynamics from a policy-maker perspective, the bulk of the literature on comovements and cycle convergence in Europe focuses on countries. ${ }^{1}$ On the other hand, the few existing works on regions tend to characterize regional fluctuations on a descriptive, rather than structural, ground, and do not investigate what lies behind regional comovements. Indeed, part of this literature assesses the differences between regional and national dynamics looking at the average of the correlation coefficients of the variables of interest, generally Gross Domestic Product (GDP), employment, (Fatàs, 1997; Clark and van Wincoop, 2001; De Grauwe and Vahaverbeke, 1993) or Gross Value Added (Montoya and de Haan, 2008), computed both within and across countries. A second vein of research is instead interested in determining the effects on regional comovements and cycle correlation of some specific factors, like industrial dissimilarity (Barrios et al. 2003), trade integration, specialization and exchange rates (Tondl and Traistaru-Siedschlag, 2011) or sectorial patterns of production (Belke and Heine, 2006).

In this respect, our paper contributes to the existing literature proposing a StructuralDynamic Factor (S-DF) perspective to study regional fluctuations. Structural Dynamic Factor Models (S-DFMs) are much popular and successful tools in the business cycle literature (Forni and Reichin, 2001; Sala, 2003; Eickmeier, 2007; Forni et al. 2009), that have been developing over the last thirty years as a combination of Dynamic Factor Models (Geweke, 1977; Sargent and Sims, 1977) and Structural-VARs (Sims, 1980; 1986). The main intuition behind this class of models is that the comovements of a large number of cross-section units may be synthesized by a small number of common factors, whose dynamics, put into a VAR form, can be used to identify the nature of the underlying structural shocks. ${ }^{2}$

Hinging on Forni and Reichlin's (2001) regional Dynamic Factor Model (DFM), here we decompose the sources of fluctuations of regional GDP and employment of 107 European

\footnotetext{
${ }^{1}$ For a comprehensive survey of this empirical literature, see de Haan et al. (2008).

${ }^{2}$ See Forni et al. (2003) for technical issues on S-DFMs, and Stock and Watson (2012) for a recent survey on DFMs.
} 
regions in the EU12 into European, national and local drivers. As in the shock accounting literature (e.g., Clark and Shin, 2000; Kose et al. 2003), the share of the overall variance explained by the European component is a proxy of business cycle comovements, capturing the probability for each region to be hit by common shocks. Whether local factors prevail, the likelihood of asymmetric dynamics increases, reducing the efficiency of creating a common currency area. Thus, the role of common shocks becomes crucial in order to preserve cohesion.

Respect to the original model, where only GDP dynamics are observed, here we move to a multivariate framework. This allows to focus on two key macroeconomic variables at once and enrich the discussion with the structural analysis of the common shocks, as in Forni and Reichlin (1998). To the best of our knowledge, this is the first attempt to identify the nature of the drivers of regional comovements in Europe. Our strategy identifies the main positive driver of GDP, a prevalently positive shock explaining as much as possible of GDP forecast error variance over a 5 year horizon, and shows how this shock could be related to productivity. A multivariate framework is generally preferable in terms of policy implications, since it provides a more complete picture of the investigated phenomenon and would suggest which economic dimensions should be monitored in order to preserve cohesion and design specific funding programs. Moreover, a focus on these two variables is motivated by the relevance their joint dynamics have for policy evaluations, as it is clear reading the Reports on Regional Cohesion, published by the European Commission since 1996.

In order to characterize better regional dynamics, we estimate the Impulse Response Functions (IRFs) of regions to the identified shock, comparing regions with high and low variance explained by the European component. Indeed, similarity of responses to the same shocks is crucial for regions with high EU component shares: since they are prevalently affected by European shocks, different reactions would result in divergent regional patterns. The degree of similarity of regional responses is assessed comparing the sign and the magnitude of the regional IRFs to the response of the corresponding EU aggregates, that as we shall see, are the weighted average of each variable across region and nations.

In light of the importance of the structural analysis in our approach, Forni and Reichlin's (2001) DFM is undoubtedly the most suitable for regional structural analysis, compared to the other options available in the S-DFM literature. Indeed, respect to the approximate DFMs (Stock and Watson, 2002; Forni et al. 2000) ${ }^{3}$, it separates the intermediate component from the idiosyncratic one, i.e. it allows to assess the role of national factors in the overall regional dynamics. At the same time, respect to more recent versions of hierarchical models ${ }^{4}$ (Hallin and Liska 2008; Ng et al. 2008), Forni and Reichlin's (2001) approach provides a natural framework to the structural analysis, which can be performed

\footnotetext{
${ }^{3}$ In the approximate DFM, variables are decomposed into a common component, accounted for by the common factors, and an idiosyncratic part, specific for each variable.

${ }^{4}$ In hierarchical models, there exist intermediate factors, that are common to a block of observations only.
} 
directly on the aggregate model, i.e. on the weighted average of variables. ${ }^{5}$

Our sample includes nine European countries, observed at NUTS1 and, where possible, NUTS2 level of disaggregation, over the period 1977-1995. A focus on the earliest stages of the European Monetary Union (EMU) foundation avoids explicitly taking into account structural breaks in regional dynamics documented elsewhere in the European business cycle literature. ${ }^{6}$ To show that this model can capture relevant features of regional dynamics in Europe, we shall compare the predictions of the model with the main stylized facts on European regions over the pre-Maastricht period. The picture of Europe that we thus propose can be validated in light of the main existing stylized facts on both regions and countries, suggesting that this technique captures essential features of the European premonetary union experience and in turn provides new interesting insights into the regional synchronization dynamics that can contribute to the existing literature and can be used to interpret also the following period.

Following the lines of this Introduction, the remainder of the paper is organized as follows. Section 2 describes the methodology for the estimation of the model. The empirical application and the comments on the results are the object of Section 3, while section 4 concludes. Technical issues not included in the core of the paper can be found in the Appendix.

\section{Model and Methodology}

The model is a generalization to the $\mathrm{M}$ variables- $\mathrm{M}$ shocks framework of the simple one variable-one shock dynamic factor model described in Forni and Reichlin (2001).

Consider a M-vector of zero-mean, stationary variables, $\mathbf{x}_{t}^{i j}=\left[x_{1 t}^{i j}, \ldots x_{m t}^{i j}, \ldots x_{M t}^{i j}\right]$, observed in region $i$, country $j$, time $t$, for $j=1, \ldots J ; i=1, \ldots I^{j} ; t=1, \ldots T$. Each variable $x_{m t}^{i j}$ can be decomposed into a European, national and local component, respectively function of a vector of common, intermediate and idiosyncratic shocks, such that

$$
x_{m t}^{i j}=E C_{m t}^{i j}+N C_{m t}^{i j}+L C_{m t}^{i j}=\boldsymbol{a}_{m}^{i j}(L)^{\prime} \boldsymbol{e}_{t}+\boldsymbol{b}_{m}^{i j}(L)^{\prime} \boldsymbol{n}_{t}^{j}+\boldsymbol{c}_{m}^{i j}(L)^{\prime} \boldsymbol{l}_{t}^{i j}
$$

$\boldsymbol{e}_{t}, \boldsymbol{n}_{t}^{j}$ and $\boldsymbol{l}_{t}^{i j}$ are $M \times 1$ vectors of unobserved white noises, with zero mean and identity covariance matrix, mutually uncorrelated at all leads and lags; similarly, $\boldsymbol{a}_{m}^{i j}(L)$, $\boldsymbol{b}_{m}^{i j}(L)$ and $\boldsymbol{c}_{m}^{i j}(L)$ are $M \times 1$ vectors of rational functions in the lag operator $(L)$, assumed of infinite order and square-summable. As in Forni and Reichlin (2001), shocks are identified according to their effects and not their origin; in this respect, a shock coming from a specific

\footnotetext{
${ }^{5}$ Indeed, in cross-country analyses with national-level variables (e.g., Eickmeir 2007), shocks are generally identified looking at their effect on some key variables - like GDP - in a leading country (e.g. the US). In a regional framework, instead, the choice of the benchmark is not as straightforward, since it is not easy to identify a leading region which can be used as reference for the other cross-section units.

${ }^{6}$ The existence of a "Maastricht effect", leading to higher synchronization in Europe after the official creation of the EMU, is reported, among others, in Montoya and de Haan (2008) and Altavilla (2004).
} 
country but having effects on all the regions in Europe should be interpreted as European, and not as national.

The extension to the $M$-dimension framework does not change the basic ideas behind the estimation methods described by Forni and Reichlin (2001), to whom we refer for technical details. However, the multivariate case requires a structural analysis for the identification of the shocks and the estimation of the impulse response functions; the resulting methodology is thus a combination of Forni and Reichlin's (2001) dynamic factor model and Forni and Reichlin's (1998) structural dynamic factor model, both sharing the same factor approach to disaggregated business cycle dynamics.

The general underlying idea is that we need a proxy for the unobserved factors, in order to estimate equation (1). These proxies are the $M J$ national aggregates, obtained by averaging the $M$ variables $x_{m t}^{i j}, m=1, \ldots M$, across regions in the same country, for all $J$ countries, and the $M$ European aggregates, given by the average of the $J$ national aggregates across countries, for each variable. Indeed, for the Weak Law of Large Numbers (WLLN), Forni and Reichlin (1998) show that in these aggregates the non-common components ${ }^{7}$ asymptotically disappear when $J$ and $I^{j}$ are sufficiently large. In this way, since the resulting aggregates are linear combinations of the underlying common shocks, they can be used as regressors in (1) and the model could be estimated by simple Ordinary Least Squares (OLS), equation by equation.

If we consider a weighted, rather than a simple, average when aggregating across $i$ (i.e., regions), and then across $j$ (i.e., countries), we have a potentially infinite number of aggregates to be used as regressors in (1). Among them, however, Forni and Reichlin (2001) identify the most efficient ones as those minimizing the share of the total variance explained by the non-common component ${ }^{8}$ in each aggregate, i.e. the principal component of the matrices $\Sigma_{m}^{j-1} \Psi_{m}^{j}$ and $\Sigma_{m}^{-1} \Psi_{m}$, where $\Sigma_{m}^{j}$ and $\Psi_{m}^{j}$ are the $I^{j} \times I^{j}$ covariance matrices of - respectively $-x_{m t}^{i j}$ and its local component, while $\Sigma_{m}$ and $\Psi_{m}$ are the $J \times J$ covariance matrices of the $m^{t h}$ variable national aggregate and its non common component. ${ }^{9}$ The reciprocal of the maximum eigenvalue estimates the share of the variance of the idiosyncratic component remaining in the aggregate and can be used as a check on the quality of aggregation. $^{10}$

Once the efficient aggregates are obtained, the decomposition of each regional variable into the three components is recovered regressing each regional variable on their national

\footnotetext{
${ }^{7}$ i.e., the local component in the national aggregates and the national component in the European one.

${ }^{8}$ These aggregates - and the corresponding set of weights - are said efficient since for them the speed of convergence to a zero-ratio of the variance of the non-common component to the variance of the common one is maximized.

${ }^{9}$ Note that, since neither $\Sigma_{m}^{j}$ nor $\Sigma$ are observables, following Forni and Reichlin (2001) the estimation procedure can be initialized assuming that these matrices are a random share of respectively $\Psi_{m}^{j}$ and $\Psi^{j}$. The implied principal component is used to obtain a preliminary estimate of the model and the diagonal entries of the "new" $\Sigma_{m}^{j}$ and $\Sigma$ can be used to obtain the final aggregates.

${ }^{10}$ See Forni and Reichlin (2001) for a formal proof.
} 
and European aggregates and rearranging the terms. ${ }^{11}$ The three components $E C_{m t}^{i j}$, $N C_{m t}^{i j}$ and $L C_{m t}^{i j}$ are orthogonal by assumption, since driven by orthogonal shocks, and the variance of each variable can be decomposed into the contribution of the variance of each component.

\subsection{Structural analysis}

Aggregating variables across regions and countries allows moving from the disaggregated model (1), where each variable is explained by local, national and European shocks, to the aggregated one, where the European aggregates of the variables are driven by common factors only,

$$
\boldsymbol{x}_{t} \approx \boldsymbol{A}(L) \boldsymbol{e}_{t}
$$

$\boldsymbol{x}_{t}$ is the M-vector of European aggregates obtained following the aggregation procedure described above, and $\boldsymbol{A}(L)$ is a $M \times M$ matrix of rational functions in the lag operator, whose $m^{\text {th }}$ row result from the aggregation of $\boldsymbol{a}_{m}^{i j}(L)$ across $i$ and $j$. By the starting assumption on $\boldsymbol{a}_{m}^{i j}(L), \boldsymbol{A}(L)$ is an infinite order matrix of square-summable linear filters. Thus, assuming equality in (2), the Wold representation of the covariance stationary process $\boldsymbol{x}_{t}$ is given by

$$
\boldsymbol{x}_{t}=\boldsymbol{A}(L) \boldsymbol{A}(0)^{-1} \varepsilon_{t}
$$

where $\varepsilon_{t}$ is a $M \times 1$ vector of white noises, resulting from the linear combination of the original shocks, $\varepsilon_{t}=\boldsymbol{A}(0) \boldsymbol{e}_{t}$.

Following Forni and Reichlin's (1998) intuition, a structural analysis can thus be performed on the aggregated model (3), referring to the traditional Structural VAR approach. ${ }^{12}$ Inverting (3), ${ }^{13}$ we obtain the reduced-form VAR representation of the aggregated model, which can also be written as

$$
\boldsymbol{x}_{t}=\left[\frac{\boldsymbol{I}_{M}-\boldsymbol{A}(0) \boldsymbol{A}(L)^{-1}}{L}\right] \boldsymbol{x}_{t-1}+\varepsilon_{t}=\mathfrak{A}(L) \boldsymbol{x}_{t-1}+\varepsilon_{t}
$$

where $\mathfrak{A}(L)$ is a $M \times M$ polynomial matrix of generic finite order $p$. Note that equation (4) can be estimated by OLS, using the European aggregates as regressors, obtaining an estimate of $\mathfrak{A}(L)$ and $\varepsilon_{t}$. The estimated $M \times M$ covariance matrix of the VAR innovations is $\boldsymbol{\Omega}$. The matrix of the unobserved parameters capturing the effects of the European shocks on the European Aggregates, $\boldsymbol{A}(L)$, can thus be identified using the information

\footnotetext{
${ }^{11}$ A detailed description of the estimation procedure for the univariate case can be found in Forni and Reichlin's (2001) paper, while the extension to the M-variable case is reported in Appendix A.

${ }^{12}$ The number of common shocks is here assumed equal to $M$, and so $M$ aggregates are sufficient in order to identify $\boldsymbol{e}_{t}$.

${ }^{13}$ We are assuming that $\boldsymbol{A}(L)$ is invertible, which implies that shocks are fundamental for $\boldsymbol{x}_{t}$, i.e. they belong to the space spanned by the present and past of $\boldsymbol{x}_{t}$ (Forni et al. 2003).
} 
contained in $\mathfrak{A}(L)$ and $\varepsilon_{t}$, as in the structural VAR literature. In particular, the only thing we need is identifying $\boldsymbol{A}(0)$, since the structural shocks $\boldsymbol{e}_{t}$ and the matrix $\boldsymbol{A}(L)$ can be derived from $\boldsymbol{e}_{t}=\boldsymbol{A}(0)^{-1} \boldsymbol{\varepsilon}_{t}$ and $[\boldsymbol{I}-\mathfrak{A}(L) L]^{-1} \boldsymbol{A}(0)$ respectively.

Imposing orthonormality of the shocks, (3) becomes

$$
\boldsymbol{x}_{t}=\left[\boldsymbol{A}(L) \boldsymbol{A}(0)^{-1} \boldsymbol{U}\right] \boldsymbol{U}^{-1} \varepsilon_{t}=\hat{\boldsymbol{A}}(L) \hat{\boldsymbol{e}}_{t}
$$

where $\boldsymbol{U}$ is the lower-triangular matrix derived from the Cholesky decomposition of $\boldsymbol{\Omega}$. By definition, $\boldsymbol{U} \boldsymbol{U}^{\prime}=\boldsymbol{\Omega}$. Comparing (2) with (5), $\boldsymbol{A}(L)$ is identified up to a $M \times M$ orthonormal, static ${ }^{14}$ rotation matrix $\boldsymbol{R}$, such that $\boldsymbol{R R}^{\prime}=\boldsymbol{I}$ and $\boldsymbol{e}_{t}=\boldsymbol{R}^{\prime} \hat{\boldsymbol{e}}_{t}$. This matrix contains the restrictions needed in order to identify the structural shocks; since the orthonormality assumption $\left(\boldsymbol{U}^{-1} \varepsilon_{t}=\hat{\boldsymbol{e}}_{t}\right)$ entails $M(M+1) / 2$ restrictions, we need to impose $M(M-1) / 2$ further restrictions in $\boldsymbol{R}$. In a simple two-shocks framework $(M=2)$, like the one we are exploiting in this application, only one constraint is needed, and the rotation matrix can be easily parameterized as function of a single rotation angle, $\theta$. For instance,

$$
\boldsymbol{R}=\left(\begin{array}{cc}
\sin (\theta) & \cos (\theta) \\
-\cos (\theta) & \sin (\theta)
\end{array}\right), \quad \theta=[0, \pi[
$$

but other parameterizations so that $\boldsymbol{R} \boldsymbol{R}^{\prime}=\boldsymbol{I}$ would be equivalent. Once $\boldsymbol{R}$ is selected, (5) becomes

$$
\boldsymbol{x}_{t}=\left[\boldsymbol{A}(L) \boldsymbol{A}(0)^{-1} \boldsymbol{U R}\right] \boldsymbol{e}_{t}
$$

and $\boldsymbol{A}(0)$ is identified by $\boldsymbol{U R}$. Note that the dynamic structural model parameters are univocally identified as well, since $\boldsymbol{a}_{m}^{i j}(L)^{\prime} \boldsymbol{e}_{t}=\boldsymbol{a}_{m}^{i j}(L)^{\prime} \boldsymbol{R}^{\prime} \hat{\boldsymbol{e}}_{t}=\hat{\boldsymbol{a}}_{m}^{i j}(L)^{\prime} \hat{\boldsymbol{e}}_{t}$. From here, the Impulse Response Functions for each variable and region to the European shocks are given by

$$
\frac{\partial E C_{m t+h}^{i j}}{\partial \boldsymbol{e}_{t}}
$$

\section{Empirical analysis}

In our empirical application of the extended Forni and Reichlin's (2001) model, we employ data on GDP and employment $(M=2)$ over the period 1977-1995 $(T=19)$ referring to nine EU12 countries, namely Belgium (BE), Germany (DE), Greece (GR), Spain (ES), France (FR), Italy (IT), the Netherlands (NL), Portugal (P) and the United Kingdom (UK), observed at NUTS1 or, where possible, NUTS2 level of disaggregation, to the amount of $N=107$ regions. ${ }^{15}$ As stated in the Introduction, the focus on the earlier stages

\footnotetext{
${ }^{14}$ Fundamentalness of the shocks implies that $\boldsymbol{R}$ is a constant matrix. See Forni et al. (2003).

${ }^{15}$ Variables are demeaned and expressed in growth rates. Details on data transformations can be found in Appendix B.
} 
of the European Monetary Union (EMU) process avoids explicitly taking into account possible structural breaks in regional synchronization. Moreover, the pre-monetary union period represents the ideal framework to assess the impact of the European integration policies on national and regional dynamics, since it allows to jointly study the behaviour of the core European countries while they are at very different stages of the integration process. ${ }^{16}$ The picture of Europe that we thus propose will be validated in light of the main existing stylized facts on both regions and countries, suggesting that this technique captures essential features of the European pre-monetary union experience and in turn provide new interesting insights into the regional synchronization dynamics that can be used to interpret also the following period.

Respect to Forni and Reichlin (2001), who focus on GDP growth rates only, here we consider employment growth as a further dimension. Indeed, GDP and employment are the two key variables in the literature assessing regional comovements in Europe, though they have been generally explored separately. ${ }^{17}$ In this respect, it is clear that studying their joint behaviour would provide a more exhaustive picture of regional dynamics. Indeed, income growth and improvements of employment are two key issues in the European policy debate, as witnessed by the documents and reports published by the European Commission since the early 1990s. ${ }^{18}$ As we shall see, similar adjustments of incomes coming along with more idiosyncratic patterns of employment have different implications for the European (and national) policy-makers, suggesting for instance the need to push further the labour market integration program or sustain employment with both national and regional-specific funding programs. The joint dynamics of GDP and employment are relevant also when assessing the long-run cohesion of the European Union, as highlighted in the Regional Cohesion Reports.

Moving to a multivariate framework requires that we identify the nature of the European fluctuations. According to our identification strategy, here we shall focus on the main positive driver of GDP, defined as a prevalently positive shock, explaining as much as possible of the volatility of the European (aggregate) GDP growth over a five-year forecast horizon. Focusing on a shock whose realizations are mainly positive implies that we are identifying a source of potential growth or decline, depending on the sign of the cumulated IRF of the GDP aggregate over the selected forecast horizon. Since this shock explains a relevant share of the volatility of European growth, and GDP is a good proxy of the economic performances of a country, it can be interpreted as the main driver of the European economy. The choice of GDP as a benchmark in the identification procedure is borrowed from Uhlig (2003), who also specifies that a five-year forecast horizon covers both the very

\footnotetext{
${ }^{16}$ Greece joined the European Community in 1981. Spain and Portugal became members of the European Community in 1986.

${ }^{17}$ e.g. Barrios et al. (2003) and Forni and Reichlin (2001) focus on GDP, Fatàs (1997) and Belke and Heine (2006) look at employment.

${ }^{18}$ See, for instance, the European Union "White paper on growth, competitiveness and employment" (1993) or the "Regional Cohesion Reports" regularly published since 1996.
} 
short-run (0-1 years) and the medium run (3-5 years) dynamics of GDP, i.e. the most appropriate time span to assess cycles synchronization. ${ }^{19}$

The share of the overall variance explained by the European component is a proxy for the level of regional integration, since it captures the likelihood of being affected by the common shocks for each region. As in the shock-accounting literature, a higher percentage of variance explained by common shocks is generally related to a higher degree of business cycle synchronization, since common shocks are those driving common fluctuations (de Haan et al. 2008). We thus look at the variance decompositions as a proxy of business cycle comovements (e.g., Kose et al. 2003). Rearranging the thresholds used by Forni and Reichlin (2001) to map Europe according to the European components in its regions, here the European component explains less than $42 \%$ of overall variance in low-integrated regions, while in high-integrated regions this share is greater than $70 \%$. From this variance decomposition exercise, we shall infer to what extent common, national and local shocks are responsible of regional dynamics, i.e. what is the nature of regional comovements in Europe.

Regional Impulse Response Functions (IRFs) will complete our picture of regional dynamics, since they define how regions react to common shocks. Similarity of responses to the same shocks is crucial for regions with high EU component shares: since they are prevalently affected by European shocks, different reactions would result in divergent regional patterns. In order to characterize better regional comovements, we shall focus on the IRFs to the main positive driver, which has a more direct interpretation, as we shall discuss later, and compare the dynamics of the high-integrated group to the low-integrated one. The degree of similarity of regional responses is assessed comparing the sign and the magnitude of the regional cumulated IRFs to the cumulated response of the corresponding EU aggregate, which is our natural benchmark. By low and high responses we identify the (cumulated) responses respectively below and above the EU average, while we denote by countercyclical all the (cumulated) IRFs whose sign over a five-year forecast horizon is opposite to the EU aggregate's one. ${ }^{20}$

The choice of tracking the identity of each region, estimating variance decompositions and responses to common shocks for all $i$ and $j$, gives the opportunity to make direct comparisons among all the cross section units - both across and within countries - and ultimately check to what extent geography and national borders matter when defining synchronization clubs. Indeed, when high synchronized areas do not reflect national borders, the existence of some insurance mechanism, such as redistributive fiscal policies or regionspecific funding programs that compensate dichotomies arising within countries, becomes crucial for the stability of the whole area.

\footnotetext{
${ }^{19}$ This implies we are not dealing with issues like long-run convergence or divergence of regions in Europe.

${ }^{20}$ Hence, we shall always refer to the cumulated IRFs over a five year horizon, since they capture the overall effect of the shock over the relevant horizon according to the identification strategy.
} 


\subsection{The nature of common shocks}

In order to characterize regional comovements, we shall try first to identify the nature of the shocks that are common to all the regions in Europe. More specifically, we shall focus on the main positive driver of the European economy. This shock is defined as a prevalently positive shock, explaining as much as possible of the volatility of the European GDP growth over a five-year forecast horizon. The identification strategy is a combination of two different approaches, both atheoretical and already exploited in the literature. ${ }^{21}$ The first one is borrowed from Forni and Reichlin (1998) and identifies a mainly positive shock selecting the rotations with the lowest sum of the absolute values of the negative realizations of that shock. Among these rotations, in the second step we select the one for which the Forecast Error Variance $(\mathrm{FEV})^{22}$ of GDP explained by that shock over a five-year horizon is maximized, following Uhlig (2003). As seen, using a five-year forecast horizon we cover both the very short-run (0-1 years) and the medium run (3-5 years) GDP movements, which are the most relevant for business cycle evaluations.

For the selected rotation, ${ }^{23}$ the main positive driver - hence, $e_{t}^{M P D}$ - explains $58.7 \%$ of the FEV of the aggregated GDP growth rate over a five-year forecast horizon, and a substantially lower share of employment growth (17.1\%); according to these figures, $e_{t}^{M P D}$ is not the main driver of employment. Since the European shocks are orthogonal by assumption, this results into a low correlation between GDP and employment growth, in line with a well known stylized fact concerning Europe: over the period 1983-1996, European growth was not employment-intensive, especially if compared to the US economy, and employment did not grow at the same pace as GDP. ${ }^{24}$

What emerges from the FEV decompositions is confirmed by the IRFs of the European aggregates (Figure 1). Aggregate GDP growth reacts more than employment: while GDP increases by $1.6 \%$ when the shock arises, employment is almost unaffected. Five periods after the shock, the cumulated effect on GDP is $2.6 \%$, while for employment it is less than a half $(1.2 \%)$. Note that the main positive driver of European growth is still responsible of some comovement of (aggregate) GDP and employment growth rates: this source of growth, on average, has a positive effect also on aggregate employment.

\section{(FIGURE 1 ABOUT HERE)}

The time series of the identified shock have been reported in Figure 2 (left-hand panel) along with the series of the other shock, while the right-hand panel in the same picture

\footnotetext{
${ }^{21}$ For technical details, see Appendix A.

${ }^{22}$ The $s$-steps-ahead FEV of $\boldsymbol{x}_{t}$ is variance of the error one makes while predicting $\boldsymbol{x}_{t}$ over the forecast horizon $s$.

${ }^{23}$ We performed fifteen rotations by twelve degrees (or, equivalently, by $\pi / 15$ ) over the interval $[0, \pi$ ). The selected rotation corresponds to $\theta=3 / 5 \pi$ (i.e. $\theta=108^{\circ}$ ) and the main positive driver corresponds to the first shock in $\boldsymbol{e}_{t}$.

${ }^{24}$ First Cohesion Report, European Commission (1996).
} 
shows the dynamics of European GDP growth rate over the same period. The main positive driver seems to have real nature and could be related to productivity. ${ }^{25}$ Indeed, it has few negative realizations clustered in the early 1980s, among which the most important is in 1980, during the spreading of the 1979 energy crisis. Also the negative realization in 1990 could be related to the oil price spike after Iraq's invasion of Kuwait. Moreover, this shock seems responsible of the high GDP growth during the period 1984-1989: possibly, this series of positive realizations may be related to the positive effects that the common market policies had on competition and productivity in the EU over that period (Crafts, 2012). The negative realization in 1993 seems to anticipate the period of productivity decline that Europe experienced as of the mid-1990s, especially if compared to the US productivity revival over the same period (Daveri, 2004).

The other shock is more difficult to interpret: it could be related to monetary events, but also to more general forces related to the European institutional changes. Indeed, the series of negative realizations in the 1980s could be related to the major alignments to German mark occurred after the establishment of the European Monetary System (EMS) in 1979, while the strong drop in 1992 is coherent with the contextual break down of the EMS, that substantially contributed to the dynamics of GDP growth rate in the early 1990s. At the same time, the high and positive realization in 1993 could be linked to the formalization of the European Monetary Union, stigmatized by the Maastricht Treaty.

(FIGURE 2 ABOUT HERE)

\subsection{Regional comovements: GDP}

Table 1 reports the optimal weights of national aggregates and the residual share of noncommon variance in the national and European aggregates, estimated by the reciprocal of the eigenvalue corresponding to the principal component of each aggregate. According to our results, for GDP national aggregates the highest percentage of non-common component variance is $7 \%$ in Greece, followed by $5 \%$ in Belgium, all the others standing below $2 \%-$ quite an encouraging result. For the Employment aggregates, in no national aggregate the $4 \%$ threshold is overcome, and the highest share is $3.4 \%$ in Belgium. Some less satisfactory results concern the European aggregates: while the percentage of the non European variance remaining after aggregation is quite low for GDP (3.9\%), for Employment it is really much higher $(11.5 \%)$, revealing that the non-common component plays a non negligible role for the Employment dynamics in Europe.

\section{(TABLE 1 ABOUT HERE)}

\footnotetext{
${ }^{25}$ In Forni and Reichlin's strategy, a mainly positive shock is coincident with a technology shock; the intuition is that technology shocks are prevalently positive, excepted for some negative events, like for instance oil shocks. However, we prefer to refer to the more general concept of productivity, since we do not have sufficient information, nor we can be sure we are identifying technology vs other events, like positive shocks to capital accumulation.
} 
Table 2 shows the variance of GDP and employment growth explained by the three components. These figures are the average (across regions in the same nation) of the share of the variance of these two variables explained by the European, national and local components. As already remarked, the variance of the European component measures to what extent a region is affected by shocks which are common to all the regions in the sample and can be interpreted as the degree of integration of each geographical area to the European Union. This is also a proxy of the degree of synchronization of regional GDP and employment to the European aggregate dynamics.

\section{(TABLE 2 ABOUT HERE)}

The first impression is that the European component explains the largest share of the variance of GDP growth in the Old Europe (Belgium, Germany, France, Italy and the Netherlands). Among the new member states, Spain looks the most European one, with a share close to $42 \%$, while the European component is the least important one in Greece, Portugal and the UK. GDP variability is mainly due to local factors in Greece, while national shocks are the main source of variation in Portugal and the UK.

These results stand to reason. Indeed, Portugal, UK and Greece are the least integrated countries also according to Forni and Reichlin's (2001) findings. For Greece, Portugal and, to a lesser extent, Spain, a lower weight of the European component is consistent with their new-member status, since for instance trade, financial and institutional interdependences are not as developed as in the older member states. ${ }^{26}$ For the UK, similar evidences come, for instance, from Barrios et al. (2003), who show that, over the period 1966-97, the UK regions were lowly correlated with a sample of European countries, while the correlation within borders was high.

When moving to the regional figures, the national dimension is not clearly recognizable. Indeed, comparing the groups of the lowest and highest integrated regions (Table 3), Europe does not seem perfectly split into high and low integrated countries and inner differences are now evident for the Old-Europe countries. If we exclude the lowest integrated countries Greece, UK and Portugal - all the other members have both low and high-integrated regions within their borders, confirming the view that regional dimensions matter (Fatàs, 1997, Tondl and Traistaru-Siedschlag, 2011). Similarly, we do observe that, excluding Portugal and the UK, in almost all the regions of the other countries the national component is overcome by European and local factors together, meaning that the national dimension is marginal when explaining GDP variability: Europe consists of regional, rather than national economies (Forni and Reichlin, 2001). When the national dimension is marginal, divergences are eventually more likely to arise within, rather than across countries.

Note that Berlin is in the low-integrated group; this could be explained by the transition experienced over this period towards the unification with the Eastern part. Furthermore,

\footnotetext{
${ }^{26}$ This would be in line with the idea that common policies, like trade unions or the adoption of a common currency, may affect the degree of synchronization of cycles with the other members ex post (Frankel and Rose, 1998).
} 
among the Old member states, France and Italy tend to be more dichotomous compared to Germany or the Netherlands, since regions with European component shares much below $40 \%$ - e.g., Corse or Calabria - coexist with regions whose shares are well above $70 \%$ e.g., Lombardia or Lorraine. Though these results could have been driven by the higher level of disaggregation (NUTS-2) in the former two countries, it is still coherent with the traditional view that inner dichotomies do not involve all the European countries to the same extent. ${ }^{27}$ Among the new member states, Spain looks more in line with European dynamics than Greece and Portugal and it shows greater inner dichotomies, since highly synchronized regions ${ }^{28}$ coexist with lowly synchronized ones ${ }^{29}$ while a third group lies in between, revealing the existence of heterogenous dynamics within the national borders. ${ }^{30}$

Across the highest integrated regions (Figure 3.a-d), GDP responses to the main positive driver seem quite homogeneous, both in sign and shape, and they tend to be greater than the EU average, implying a high degree of regional comovements. For the lowest integrated regions (Figures 4.a-f), the cumulated impact is positive almost everywhere; the only countercyclical response is Anatoliki Makedonia (Greece), which also results to be lowly integrated in terms of the variance explained by the common component $(9.6 \%)$ and thus performs as an outlier. The magnitude of the responses tend to be milder in this group, though a uniform path is less difficult to identify in this case. What is shared across these regions is that, independently of the level of integration, regional GDPs comove after this shock, and fostering integration, in principle, should lead to more cohesion. ${ }^{31}$

The predictions of the model looks coherent also with the regional experience of one emblematic country: Italy. Indeed, this country is traditionally characterized by inner divergences, in terms of economic performances, between North and South, ${ }^{32}$ and the Southern regions have been included among the weakest European regions as recipients of the Community structural funds since the first programming period. ${ }^{33}$ Our findings seems to confirm this view: the European component explains a low share of the overall GDP variance in four Southern regions - Sardegna, Sicilia, Basilicata and Calabria - while all the Northern regions are in the high-integrated group.

\footnotetext{
${ }^{27}$ This can be inferred from the Regional Cohesion Reports by the European Commission.

${ }^{28}$ Cataluña is in this group, while the region of Madrid is borderline, with a share close to $70 \%$.

${ }^{29}$ For instance, Baleares and Canarias. Evidences of asymmetric cycles in this part of Spain are in Villaverde (2000) and Cunado and Sanchez-Robles (2000).

${ }^{30}$ Gadea et al. (2012) compare regional cycles to national dynamics, finding that not all regions share the same Spanish path. However, their results are not directly comparable to ours, since we look at the importance of the European component and assess synchronization respect to the European aggregate, and not respect to national ones.

${ }^{31}$ It is worth remarking that trade (Krugman, 1993) or capital market integration (Kalemli-Ozcan et al. 2001) may stimulate sectoral specialization as well, increasing the probability of being affected by local-specific shocks.

${ }^{32}$ Northern regions are Piemonte, Valle d'Aosta, Liguria, Lombardia, Trentino-Alto Adige, Veneto, FriuliVenezia Giulia, Emilia -Romagna. Southern regions (including the islands) are Abruzzo, Molise, Campania, Puglia, Basilicata, Calabria, Sicilia and Sardegna).

${ }^{33}$ The first programming period ran from 1989 to 1993.
} 
Our results point also at the existence of some dynamism within the group of Southern regions. Indeed, Abruzzo and Molise are in the highly synchronized group, ${ }^{34}$ while Puglia and Campania show a medium level of synchronization, with not-negligible European component shares. The existence of many Mezzogiorni is a well accepted idea in a recent specialized literature (Viesti, 2000; Guerrieri and Iammarino 2002; 2007), that finds evidences of economic dynamism respect to the rest of the South in Abruzzo, Campania, Puglia and Molise. On the other hand, Calabria, Sicilia and Sardegna have been confirming the failure of their sectorial specialization, mainly characterized by a strengthening of slow-growing, resource-intensive sectors (Iammarino and Santangelo, 2001).

In light of these findings, the presence of low-integrated countries on the one side, and the lack of cohesion within high-integrated countries on the other side, suggest the necessity of a two-level European integration policy. For those countries that, as a whole, are not highly synchronized to the rest of Europe, it seems crucial both fostering the integration process and monitoring the evolution of local dynamics, especially where the idiosyncratic components are prevalent compared to the national ones - as, for instance, in Greece. For those high-integrated countries, that are mainly driven, on average, by common drivers, as for instance in Italy, it is rather necessary to monitor within-country patterns and foster policies aimed to reduce actual and potential inner dichotomies.

(TABLE 3 ABOUT HERE)

\subsection{Regional comovements: employment}

A different picture shows up looking at the variance decompositions of employment growth. Indeed, the European component is the most relevant one only in Belgium and, to a much lesser extent, Spain, while for the UK, France, Italy and Greece local factors are mainly responsible for the variance of this variable. On average, it seems that the main drivers of this variable are of local and national nature. This may be evidence of the existence of a persistent variety of institutional models and labour policies across the European countries, which may be responsible of the relative importance of national components, and the implicit propensity of regions (respect to countries) towards higher specialization in specific activities, so that they are more subject to sector-specific shocks (Marelli, 2006). Moreover, the existence of more constraints on labour mobility than on capital and goods makes it not likely that a shock, whatever its nature or origin is, spreads around and affects employment in all the EU regions. To some extent, the spill-over effects which may explain the importance of the EU shocks for GDP growth may be partially nullified by the segmentation of labour markets. This interpretation is consistent with the literature on the structural characteristics of european labour markets (briefly reviewed in Marelli,

\footnotetext{
${ }^{34}$ Abruzzo and Molise have been excluded from the Objective-1 funds as of the 2000-2006 programming period.
} 
2006) and with the observation that the main reforms in Europe towards more flexibility and integration of labour markets come after the period analyzed here.

Looking at the variance decompositions at the regional level (Table 4), it is confirmed that employment in the European regions is mainly explained by local and national factors. Indeed, the bulk of the regions are in the low-integrated group, while only four regions belong to the high-integrated one. Interestingly, all the regions containing the most important European capital cities - Bruxelles, Île de France, London, Antwerp - or international economic poles - Hamburg, Lombardia - do have relevant shares (greater than 50\%) of employment variance explained by common factors, implying that internationalization may be an important factor fostering the integration of regional employment dynamics. On the other hand, dichotomies both across and within countries are more likely to arise for regional employment than for GDP growth, since its sources of volatility are mainly country and region-specific. This is in line with those studies finding an increasing polarization of regions in terms of employment, reviewed in Belke and Heine (2006).

\section{(TABLE 4 ABOUT HERE)}

The group of most integrated regions (Figure 5) - Vlaams Gewest (BE), Saarland (D), Lombardia (I) and London (UK) - has responses to $e_{t}^{M P D}$ well synchronized, but we cannot describe any geographic pattern. Almost all these regions do include important economic poles, ${ }^{35}$ with international firms and networks which make them well connected and sufficiently open to foster integration in employment. The only small and peripheral region is Saarland in Germany. However, its engagement with globalization has been shaped by its industrial base and its border location (Jones et al. 2012). Indeed, it is a well connected region, endowed with a high developed transportation network, reasonably thanks to its strategic location - it shares its borders with France, Luxembourg and Germany - which allows a high degree of accessibility: this is in line with the idea that the degree of integration in employment can be influenced by factors like transportation costs (Belke and Heine, 2006).

On the other hand, the group of the low-integrated regions is numerous and heterogeneous (Figure 6.a-h), since it includes regions from all countries (with the exception of Belgium) and responses to the common shock are different in shape and sign. Since employment is mainly driven by local and national shocks, a potentially large set of factors, like characteristics of local job markets (more or less flexibility of job markets, constraints from both the demand and supply side...) and institutional factors may affect the dynamics of this variable. In this perspective, since common shocks are not a source of synchronicity for employment and regions are driven by heterogeneous forces, we can infer that regions are not cohesive in terms of employment dynamics. This result is consistent with Belke and Heine (2006), who find a declining trend of synchronicity of regional employment cycles for many European region-pairs over the period 1989-1997. Even those regions whose GDP

\footnotetext{
${ }^{35}$ Antwerp in Vlaams Gewest, Milan in Lombardia, while the city of London coincides with the region.
} 
comove after a common shock are not necessarily synchronized in terms of employment, so that GDP and employment seem driven by different factors. In this respect, monitoring divergences both within and across countries along this dimension seems a reasonable point, especially where very idiosyncratic dynamics tend to prevail, as for instance in Greece and Italy.

(FIGURES 3-6 ABOUT HERE)

\section{Conclusions}

Regional comovements are by far a key issue in the debate on the optimality of Europe as a single currency area and deserve special attention when assessing the impact of common policies on the member states and monitoring cohesion across countries. In this respect, this analysis tries to contribute to the existing small and heterogeneous literature on European regional dynamics, proposing a Structural DFM à la Forni and Reichlin (1998; 2001) that gives detailed insights on both across and within-country patterns of behaviour of regions in the EU12. We do believe this model could substantially contribute to the existing European literature on regional synchronization along several dimensions, since it allows to assess the relative importance of European, national and local shocks in the observed regional dynamics and provides a natural framework for structural analysis. Moreover, tracking the identity of each region, it allows direct geographic comparisons of regional dynamics.

The results of our empirical exercise offer a quite complex picture of the pre-Maastricht European Union and of its regional structure, and can be summarized as follows. First, both variance decompositions and IRFs show that regions are more synchronized in terms of GDP dynamics than of Employment. This reflects, on the one hand, a somewhat successful integration of regional economies through common trade, monetary and economic policies or financial interdependences and, on the other hand, a much slower integration of labour markets, confirming the existence of tighter constraints on the labour mobility side. Moreover, GDP and Employment seem to be driven by different forces: while very common and very local factors are prevalent in the former, national and local-specific components dominate in the latter, and the main positive driver of GDP growth contributes only marginally to the Employment growth dynamics. Since dichotomies both within and across countries are more likely to arise in terms of Employment, this result highlights the importance of increasing labour market integration on the one hand, and the need of a special focus on regional Employment dynamics, carried along with the one on income growth, in order to design proper policies and achieve more cohesion across different parts of Europe.

Second, GDP dynamics are regional, rather than national. Indeed, GDP is mainly driven by common and idiosyncratic components, meaning that the national dimension is generally not prevalent. Moreover, though the group of most integrated regions excludes 
some countries as a whole - UK, Portugal and Greece - it does not include all the regions in the Old member states, implying that the most synchronized part of Europe has no precise national dimension. This suggests the necessity of a two-level European integration policy, which on the one hand fosters the integration process of the less synchronized countries and monitors the evolution of local dynamics where the idiosyncratic components are prevalent - as in Greece - and on the other hand, monitors within-country patterns and foster policies aimed to reduce actual and potential inner dichotomies in the high-integrated countries. Monitoring synchronization at the regional level is crucial, since the evolution towards less synchronized regions would reduce the optimality of extreme integration policies, like the choice of a common currency.

Regional patterns of synchronization appear really more complicated when looking at the behaviour of employment, for which a very small group of regions is synchronized and international linkages and good interconnections seem important drivers. This result may be driven by the structural segmentation of labour markets - low flexibility of job markets, constraints from both the demand and supply side, institutional factors. In this respect, monitoring divergences both within and across countries along this dimension seems a reasonable point, especially in those countries where very idiosyncratic dynamics tend to prevail, as for instance in Greece and Italy.

These results show that the predictions of the model are rather in line with the observed regional dynamics and stylized facts of Europe, as the focus on Italy pointed out, but also provide new insights on regional patterns of behaviour in Europe, contributing to build up a set of evidences that could be compared with the post-Maastricht period and help interpret the most recent events affecting the cohesion of the European Union and its stability. In this respect, our works leaves open the issue of the effect of the implementation of the EMU on regional comovements and national cohesion, that could be addressed extending the dataset to the most recent years, and possibly allowing for time-varying variances and parameters.

\section{References}

[1] Altavilla, C. (2004), "Do EMU Members Share the Same Business Cycle?", Journal of Common Market Studies, Wiley Blackwell, vol. 42(5), pages 869-896, December.

[2] Barrios, S., M. Brülhart, R.J.R. Elliott, and M. Sensier (2003), "A Tale of Two Cycles: Co-fluctuations Between UK Regions and the Euro Zone", The Manchester School Vol 71 No. 3 June 2003.1463-6786 265-292.

[3] Belke, A., and J.M. Heine (2006), "Specialization Patterns and the Synchronicity of Regional Employment Cycles in Europe", International Economics and Economic Policy, Springer, vol. 3(2), pages 91-104, November. 
[4] Clark, T.E., and K. Shin (2000), "The sources of fluctuations within and across countries", in: G. Hess and E. van Wincoop (eds.), Intranational Macroeconomics, Cambridge, University Press, Cambridge, pp. 189-217.

[5] Clark, T. E., and E. van Wincoop (2001), "Borders and Business Cycles", Journal of International Economics, Vol. 55, pp. 59-85.

[6] Crafts, N. (2012), "Western Europe's Growth Prospects: an Historical Perspective", CAGE Online Working Paper Series 70, Competitive Advantage in the Global Economy (CAGE).

[7] Cuñado, J., and S.R. Blanca (2000), "Regional Disparities And Asymmetric Shocks: The Case Of The Spanish Regions", ERSA conference papers, August 2000.

[8] Daveri, F. (2004), "Why is there a Productivity Problem in the EU?", CEPS Working Documents No. 205, 1 July 2004.

[9] De Grauwe, P. and W. Vanhaverbeke (1993), "Is Europe an Optimum Currency Area?: Evidence from Regional Data", in P. R. Masson and M. P. Taylor (eds), Policy Issues in the Operation of Currency Unions, Cambridge, Cambridge University Press.

[10] de Haan, J., R. Inklaar, and J. Richard (2008), "Will business cycles in the Euro Area converge: a critical survey of empirical research", Journal of Economic Surveys, Vol. 22, Issue 2, pp. 234-273, April 2008.

[11] Eikmeier, S. (2007), "Business Cycle Transmission from the US to Germany - A Structural Factor Approach", European Economic Review, Volume 51, Issue 3, April 2007, Pages 521-551.

[12] European Commission (1996; 1999), "First Cohesion Report" and "Sixth Periodic Report on the social and economic situation and development of Regions in the European Union", http://ec.europa.eu/regional_policy/sources/docoffic/official/repor_en.htm

[13] European Commission (1993), "Growth, competitiveness, employment: The challenges and ways forward into the 21 st century".

[14] Fatás, A. (1997), "Countries or Regions? Lessons from the EMS Experience", European Economic Review, 41, 743-751.

[15] Forni, M., D. Giannone, M. Lippi, and L. Reichlin (2009), "Opening the Black Box: Structural Factor Models with Large Cross Sections", Econometric Theory, 25, 13191347.

[16] Forni, M., M. Hallin, M. Lippi, and L. Reichlin (2000), "The Generalized Factor Model: Identification And Estimation", Review of Economics and Statistics, 82, 540-554. 
[17] Forni, M., M. Lippi, and L. Reichlin (2003), "Opening the black box: structural factor models versus structural VARs", ECARES-ULB Working Paper, www.dynfactors.org.

[18] Forni, M., and L. Reichlin (1998), "Let's Get Real: A Dynamic Factor Analytical Approach to Disaggregated Business Cycle", Review of Economic Studies, 65, 453474 .

[19] Forni, M., and L. Reichlin (2001), "Federal policies and local economies: Europe and the US", European Economic Review, 45, 109-134.

[20] Frankel, J. A., and A. K. Rose (1998), "The endogeneity of the optimum currency area criteria", The Economic Journal 108 (July), 1009-1025.

[21] Gadea, M.D., A. Gómez-Loscos, and A. Montañés (2012), "Cycles inside cycles: Spanish regional aggregation", SERIEs December 2012, Volume 3, Issue 4, pp 423-456.

[22] Geweke, J. (1977), "The Dynamic Factor Analysis of Economic Time Series", in Latent Variables in Socio-Economic Models, ed. by D.J. Aigner and A.S. Goldberger, Amsterdam: North-Holland.

[23] Guerrieri, P., and S. Iammarino (2007), "Dynamics of export specialization in the regions of the Italian Mezzogiorno: persistence and change", Regional Studies 41, 933-947.

[24] Guerrieri, P., and S. Iammarino (2002), "Vulnerabilità e regioni nell'Unione Europea: un esercizio sul Mezzogiorno italiano", Italian Journal of Regional Science (Scienze Regionali), 2, pp. 5-28.

[25] Hallin M., and R. Liska (2008), "Dynamic factors in the Presence of Block Structure", EUI Working Papers, ECO 2008/22.

[26] Iammarino, S., and G.D. Santangelo (2001), "The Evolution of Trade and Technology in the Italian regions," ERSA conference papers, European Regional Science Association.

[27] Jones, L., M. Woods, B. Nienaber, and W. Frys (2012), "Case Study Contextual Report 5: Saarland", Derreg.

[28] Kalemli-Ozcan, S., B. Sorensen, and O. Yosha (2001), "Economic Integration, Industrial Specialization, and the Asymmetry of Macroeconomic Fluctuations", Journal of International Economics, Vol. 55, pp. 107-137.

[29] Kose, M. A, C. Otrok, and C.H. Whiteman (2003), "International Business Cycles: World, Region, and Country-Specific Factors", The American Economic Review, Vol. 93, No. 4 (Sep., 2003), pp. 1216-1239. 
[30] Krugman, P. (1993), "Lessons of Massachusetts for EMU", in: F. Torres and F. Giavazzi (Eds.), Adjustment and Growth in the European Monetary Union, 241-261. Cambridge: Cambridge University Press.

[31] Marelli, E. (2006), "Regional employment dynamics in the EU: structural outlook, comovements, clusters and common shocks", in: Caroleo, F.E., De Stefanis, S. (Eds.), The European Labour Market, AIEL Series in Labour Economics 2006, pp 89-121.

[32] Montoya, L.A., and J. de Haan (2008), "Regional Business Cycle Synchronization in Europe?", International Economics and Economic Policy, July 2008, Volume 5, Issue 1-2, pp 123-137.

[33] Ng S., E. Moench, and S. Potter (2008), "Dynamic Hierarchical factor Models", mimeo, Columbia University.

[34] Sala, L. (2003), "Monetary transmission in the Euro Area: A factor model approach", University Bocconi.

[35] Sargent, T.J., and C.A. Sims (1977), "Business Cycle Modeling Without Pretending to Have Too Much A-Priori Economic Theory", in New Methods in Business Cycle Research, ed. by C. Sims et al., Minneapolis: Federal Reserve Bank of Minneapolis.

[36] Sims, C.A. (1986), "Are Forecasting Models Usable for Policy Analysis?", Quarterly Review of the Federal Reserve Bank of Minneapolis, 10, pp. 2-16.

[37] Sims, C.A. (1980), "Macroeconomics and Reality", Econometrica 48:1-48.

[38] Stock, J.H., and M.W. Watson (2002), "Macroeconomic Forecasting Using Diffusion Indexes", Journal of Business and Economic Statistics, 20, 147-162.

[39] Stock, J.H., and M.W. Watson (2012), "Dynamic Factor Models", Oxford Handbooks Online. 2012-09-18, Oxford University Press.

[40] Tondl, G., and I. Traistaru-Siedschlag (2011), "Regional Output Growth Cycle Synchronisation with the Euro Area", Empirica, Springer, vol. 38(2), pages 203-221, May.

[41] Uhlig, H. (2003), "What moves real GNP?", manuscript.

[42] Viesti, G. (2000), "La proiezione internazionale dei distretti meridionali del made in Italy", in Rapporto Istat-Ice 1999-2000, Rome.

[43] Villaverde, J. (2000), "Emu and Regional Disparities In Spain", ERSA conference papers, August 2000. 


\section{A Estimation issues}

Let us call $w_{m}^{i j}$ the optimal weight given to region $i$, country $j$, for the generic $m^{\text {th }}$ variable, and $w_{m}^{j}$ the optimal weight given to country $j$ for the $m^{t h}$ national aggregate. By definition, the national aggregate of the $m^{\text {th }}$ variable in country $j$ is given by

$$
x_{m t}^{j}=\sum_{i=1}^{I^{j}} w_{m}^{i j} \cdot x_{m t}^{i j} \approx \boldsymbol{a}_{m}^{j}(L)^{\prime} \boldsymbol{e}_{t}+\boldsymbol{b}_{m}^{j}(L)^{\prime} \boldsymbol{n}_{t}^{j}
$$

where $\boldsymbol{a}_{m}^{j}(L)^{\prime}$ is the $1 \times M$ vector given by

$$
\boldsymbol{a}_{m}^{j}(L)^{\prime}=\sum_{i=1}^{I^{j}} w_{m}^{i j} \cdot \boldsymbol{a}_{m}^{i j}(L)^{\prime}
$$

and $\boldsymbol{b}_{m}^{j}(L)^{\prime}$ is the $1 \times M$ vector given by

$$
\boldsymbol{b}_{m}^{j}(L)^{\prime}=\sum_{i=1}^{I^{j}} w_{m}^{i j} \cdot \boldsymbol{b}_{m}^{i j}(L)^{\prime}
$$

while the European aggregates correspond to

$$
x_{m t}=\sum_{j=1}^{J} w_{m}^{j} \cdot x_{m t}^{j} \approx \boldsymbol{a}_{m}(L)^{\prime} \boldsymbol{e}_{t}
$$

where $\boldsymbol{a}_{m}(L)^{\prime}$ is the $1 \times M$ vector given by

$$
\boldsymbol{a}_{m}(L)^{\prime}=\sum_{j=1}^{J} w_{m}^{j} \cdot \boldsymbol{a}_{m}^{j}(L)^{\prime}
$$

Let us collect the $M$ national aggregates $x_{m t}^{j}$ in a single $M \times 1$ vector for each country $j$, and the $M$ European aggregates $x_{t}$ in a $M \times 1$ vector, so that (A.1) and (A.2) become, respectively,

$$
\boldsymbol{x}_{t}^{j} \approx \boldsymbol{A}^{j}(L) \boldsymbol{e}_{t}+\boldsymbol{B}^{j}(L) \boldsymbol{n}_{t}^{j}
$$

and

$$
\boldsymbol{x}_{t} \approx \boldsymbol{A}(L) \boldsymbol{e}_{t}
$$

where $\boldsymbol{A}^{j}(L)$ and $\boldsymbol{B}^{j}(L)$ are $M \times M$ matrices of rational functions in the lag operator whose $m^{\text {th }}$ rows are given, respectively, by $\boldsymbol{a}_{m}^{j}(L)^{\prime}$ and $\boldsymbol{b}_{m}^{j}(L)^{\prime}$, while $\boldsymbol{A}(L)$ is a $M \times M$ matrix 
of rational functions in the lag operator, whose $m^{\text {th }}$ row is given by $\boldsymbol{a}_{m}(L)^{\prime}$. Assuming equality in (A.4) and invertibility of $\boldsymbol{A}(L)$, the vector of the European shocks results to be a linear combination of the present and the past of the European aggregates collected in $\boldsymbol{x}_{t}$ and the European aggregates could be used in principle as regressors in (1).

As a consequence, we can estimate $M J$ regressions

$$
x_{m t}^{j}=\boldsymbol{\alpha}_{m}^{j}(L)^{\prime} \boldsymbol{x}_{t}+N_{m t}^{j}, \quad j=1, \ldots J ; m=1, \ldots M
$$

where $\boldsymbol{\alpha}_{m}^{j}(L)$ is a $M \times 1$ vector of parameters estimated by OLS, and the order of the lags is defined by some arbitrary criterion (like, for instance, an F-test on the specification). More compactly,

$$
\boldsymbol{x}_{t}^{j}=\boldsymbol{A} \boldsymbol{L} \boldsymbol{F} \boldsymbol{A}^{j}(L) \boldsymbol{x}_{t}+\boldsymbol{N}_{t}^{j}, \quad j=1, \ldots J
$$

where $\boldsymbol{A L F} \boldsymbol{A}^{j}(L)$ is a $M \times M$ matrix of rational functions in the lag operator whose $m^{\text {th }}$ row corresponds to $\boldsymbol{\alpha}_{m}^{j}(L)^{\prime}$, and $\boldsymbol{N}_{t}^{j}$ is a $M \times 1$ vector collecting the residuals $N_{m t}^{j}$, $m=1, \ldots M$.

Similarly, each regional variable $x_{m t}^{i j}$ can be written as a function of the $M$ European aggregates collected in $\boldsymbol{x}_{t}$ and of the $M$ national aggregates corresponding to that country, $\boldsymbol{x}_{t}^{j}$.

As a result, estimating

$$
\begin{aligned}
x_{m t}^{i j} & =\boldsymbol{\alpha}_{m}^{i j}(L)^{\prime} \boldsymbol{x}_{t}+\boldsymbol{\beta}_{m}^{i j}(L)^{\prime} \boldsymbol{x}_{t}^{j}+L C_{m t}^{i j}, \\
m & =1, \ldots M ; j=1, \ldots J ; i=1, \ldots I^{j}
\end{aligned}
$$

by OLS for all the variables, all the regions and all the countries, we obtain $M N$ equations, where $N=\sum_{j} I^{j}$. Note that $\boldsymbol{\alpha}_{m}^{i j}(L)$ and $\boldsymbol{\beta}_{m}^{i j}$ are $M \times 1$ vectors of parameters, estimated by OLS, whose order of lags is again defined by some arbitrary information criterion.

The residuals of the regressions in (A.7) are an estimate of $L C_{m t}^{i j}$. Substituting (A.6) in (A.7), we obtain

$$
x_{m t}^{i j}=\boldsymbol{\alpha}_{m}^{i j}(L)^{\prime} \boldsymbol{x}_{t}+\boldsymbol{\beta}_{m}^{i j}(L)^{\prime}\left[\boldsymbol{A L F} \boldsymbol{A}^{j}(L) \boldsymbol{x}_{t}+\boldsymbol{N}_{t}^{j}\right]+L C_{m t}^{i j}
$$

Thus, $E C_{m t}^{i j}$ is simply obtained collecting all the terms depending on the European aggregates, i.e.

$$
E C_{m t}^{i j}=\boldsymbol{\alpha}_{m}^{i j}(L)^{\prime} \boldsymbol{x}_{t}+\boldsymbol{\beta}_{m}^{i j}(L)^{\prime} \boldsymbol{A} \boldsymbol{L} \boldsymbol{F} \boldsymbol{A}^{j}(L) \boldsymbol{x}_{t}
$$

while $N C_{m t}^{i j}$ can be recovered by difference.

Expressing (A.9) as function of the common shocks, replacing $\boldsymbol{x}_{t}$ with the equivalent expression in (A.6), we obtain 


$$
E C_{m t}^{i j}=\left[\boldsymbol{\alpha}_{m}^{i j}(L)^{\prime}+\boldsymbol{\beta}_{m}^{i j}(L)^{\prime} \boldsymbol{A} \boldsymbol{L} \boldsymbol{F} \boldsymbol{A}^{j}(L)\right][\boldsymbol{I}-\mathfrak{A}(L) L]^{-1} \boldsymbol{U R} \boldsymbol{e}_{\boldsymbol{t}}
$$

that identifies the Impulse Response Function of variable $m$, in region $i$, country $j$ is to the common shocks.

This estimation procedure is based on the assumption that a weighted average of the variables kills the non-common components off, so that we are left with optimal aggregates. However, since the number of cross-section units is necessarily finite, these averages still include a measurement error, and this affects the usual properties of the OLS estimator. In this respect, some theoretical results have been provided by Forni and Reichlin (1998) only for the case of the simple average estimator. They show that consistency of the parameters is reached only if we let both $T$ (time dimension) and $N$ (cross-section dimension) go to infinity; moreover, the relative rate at which $T$ and $N$ approach infinity does not matter. For the weighted-average case, no theoretical results have been provided yet. However, Forni and Reichlin (2001) perform a set of Monte Carlo simulations and find that the weighted average estimators outperform the simple average ones for all $T$ and $N$. Moreover, neither standard errors nor confidence bands are available for the estimates and impulse response functions, and this inference problem has been remarked also by Forni and Reichlin (1998).

\section{A.1 Identification strategy}

In order to identify a prevalently positive shock, define

$$
\tilde{\boldsymbol{e}}_{t}=\boldsymbol{e}_{t}+\boldsymbol{\mu}_{\tilde{e}}
$$

where $\boldsymbol{\mu}_{\tilde{e}}$ is the vector of the means of the common shocks. Similarly, for the vector of the aggregates, we have

$$
\tilde{\boldsymbol{x}}_{t}=\boldsymbol{x}_{t}+\boldsymbol{\mu}_{\tilde{x}}
$$

where $\boldsymbol{\mu}_{\tilde{x}}$ is the vector of the means of the European aggregates. It holds that

$$
\tilde{\boldsymbol{x}}_{t}=\boldsymbol{x}_{t}+\boldsymbol{\mu}_{\tilde{x}}=\boldsymbol{A}(L) \tilde{\boldsymbol{e}}_{t}=\boldsymbol{A}(1) \boldsymbol{\mu}_{\tilde{e}}+\boldsymbol{A}(L) \boldsymbol{e}_{t}
$$

If $\operatorname{det}(\boldsymbol{A}(1))$ is different from zero, $\boldsymbol{A}(1)$ is invertible and

$$
\boldsymbol{\mu}_{\tilde{e}}=\boldsymbol{A}(1)^{-1} \boldsymbol{\mu}_{\tilde{x}}
$$

Different rotations identify different vectors $\boldsymbol{e}_{t}$, that correspond to different $\tilde{\boldsymbol{e}}_{t}$ and $\boldsymbol{\mu}_{\tilde{e}}$. Denoting by $\tilde{e}_{t}^{M P}$ the series of the mainly positive shocks, $\boldsymbol{R}$ is selected so that the sum of the absolute values of the negative realizations of $\tilde{e}_{t}^{M P}$ is minimized. Alternatively, Forni and Reichlin (1998) show that, assuming normality of the shocks, the sum of the absolute values of the negative realizations is minimized when the mean of $\tilde{e}_{t}^{M P}$ is maximized, since 
variance is not influenced by the rotations. As a consequence, one could either minimize the absolute sum of negative values or maximize the shock mean. Here we follow the former method.

In order to identify the main driver of a vector of variables $\boldsymbol{x}_{t}$ over a specific forecast horizon $H$, we need to derive the share of the overall forecast error variance of $\boldsymbol{x}_{t}$ explained by each shock over $H$. Using basic VAR definitions, and sticking to the notation used throughout the paper, the $H$-step-ahead forecast error for $\boldsymbol{x}_{t}$ is given by

$$
\sum_{h=0}^{H}\left[[\boldsymbol{I}-\mathfrak{A}(L) L]^{-1}\right]^{h} \varepsilon_{t+h}=\sum_{h=0}^{H}\left[[\boldsymbol{I}-\mathfrak{A}(L) L]^{-1}\right]^{h} \boldsymbol{U R} \boldsymbol{e}_{t+h}
$$

The variance of the $H$-step-ahed forecast error, also said FEV, can be decomposed into the contribution of each orthogonal shock $(k)$ to the overall variance:

$$
H_{-} F E V=\sum_{k=1}^{M} \sum_{h=0}^{H}\left\{\left[[\boldsymbol{I}-\mathfrak{A}(L) L]^{-1}\right]^{h} \boldsymbol{u} \boldsymbol{r}_{k}\right\}\left\{\left[[\boldsymbol{I}-\mathfrak{A}(L) L]^{-1}\right]^{h} \boldsymbol{u} \boldsymbol{r}_{k}\right\}^{\prime}
$$

where $k$ denotes the shock, $m$ the variable of interest and $\boldsymbol{u} \boldsymbol{r}_{k}$ is the $k^{\text {th }}$ column of the matrix $\boldsymbol{U R}$ identified in the main text. 


\section{B Data}

The dataset covers 107 European regions whose GDP and Employment are observed with annual frequency for the period 1977-1995. The countries involved are Belgium, western Germany, Greece, Spain, France, Italy, the Netherlands, Portugal and the UK. The level of disaggregation is NUTS2, according to the European nomenclature, for all countries but Belgium, Germany, the Netherlands and the UK, whose data are available only at the NUTS1 level for that period. The details on the geographic area concerned in the analysis are in Table A1.

The main source of the data is the CRENoS Data Bank On European Regions. GDP is Gross Domestic Product in Purchasing Power Standard (PPS) at constant prices, 1990 $=100$. EMP is total employment measured as thousands of employed people in the region. For all the series, natural logarithms have been taken and the first difference computed in order to obtain the growth rate of the variables. Finally, the mean has been subtracted from the resulting series.

Table A.1 - List of the countries included in the analysis

\begin{tabular}{|c|c|c|c|}
\hline Country & Disaggregation & Regions & Excluded \\
\hline Belgium & NUTS1 & 3 & \\
\hline Germany & NUTS1 & 11 & Eastern Germany \\
\hline Greece & NUTS2 & 13 & \\
\hline Spain & NUTS2 & 17 & $\begin{array}{l}\text { Ciudad Autónoma de Ceuta, } \\
\text { Ciudad Autónoma de Melilla }\end{array}$ \\
\hline France & NUTS2 & 22 & Guadelupe, Martinique, Guyane, Réunion \\
\hline Italy & NUTS2 & 20 & \\
\hline Netherlands & NUTS1 & 4 & \\
\hline Portugal & NUTS2 & 5 & $\begin{array}{l}\text { Região Autónoma dos Açores } \\
\text { Região Autónoma de Maidera }\end{array}$ \\
\hline UK & NUTS1 & 12 & \\
\hline
\end{tabular}




\section{Tables and Graphs}

Table 1 - Optimal weights by country and non -common component residual share

\begin{tabular}{l|cc|cc}
\hline \hline Country & $\mathrm{w}_{g d p}$ & $\boldsymbol{\lambda}_{g d p}$ & $\mathrm{w}_{e m p}$ & $\boldsymbol{\lambda}_{e m p}$ \\
\hline Germany & 0.12 & 0.009 & 0.04 & 0.003 \\
UK & 0.02 & 0.018 & 0.48 & 0.006 \\
France & 0.36 & 0.012 & 0.10 & 0.018 \\
Italy & 0.22 & 0.009 & 0.02 & 0.029 \\
Belgium & 0.08 & 0.052 & 0.29 & 0.034 \\
Netherlands & 0.08 & 0.012 & 0.01 & 0.008 \\
Greece & 0.02 & 0.069 & -0.02 & 0.002 \\
Spain & 0.08 & 0.017 & 0.08 & 0.010 \\
Portugal & 0.01 & 0.010 & 0.00 & 0.018 \\
\hline EU & - & 0.039 & - & 0.115 \\
\hline \hline
\end{tabular}

Table 2 - Variance decompositions by country and component (\% of overall variance)

\begin{tabular}{l|ccc|ccc}
\hline \hline Country & $\mathrm{EC}_{g d p}$ & $\mathrm{NC}_{g d p}$ & $\mathrm{LC}_{g d p}$ & $\mathrm{EC}_{e m p}$ & $\mathrm{NC}_{e m p}$ & $\mathrm{LC}_{e m p}$ \\
\hline Germany & 65.2 & 26.1 & 8.7 & 39.7 & 50.7 & 9.6 \\
UK & 26.4 & 44.4 & 29.2 & 29.2 & 27.3 & 43.6 \\
France & 64.6 & 11.6 & 23.8 & 36.1 & 21.8 & 42.1 \\
Italy & 66.8 & 11.2 & 22.0 & 24.4 & 24.3 & 51.3 \\
Belgium & 53.1 & 28.1 & 18.8 & 68.7 & 19.1 & 12.2 \\
Netherlands & 58.3 & 29.4 & 12.3 & 17.3 & 78.3 & 3.4 \\
Greece & 26.8 & 29.0 & 44.2 & 18.9 & 19.9 & 61.1 \\
Spain & 41.7 & 28.9 & 29.4 & 46.3 & 26.7 & 27.7 \\
Portugal & 15.0 & 42.8 & 42.2 & 4.3 & 72.1 & 23.7 \\
\hline \hline
\end{tabular}

Note: average across regions, by country 
Table 3 - Ranking of regions according to the variance of GDP European component (\%)

\begin{tabular}{|c|c|c|c|c|}
\hline REGION & COUNTRY & EC & $\mathrm{NC}$ & LC \\
\hline Centro $(\mathrm{P})$ & $\mathrm{P}$ & 1.3 & 52.8 & 45.9 \\
\hline Berlin & DE & 3.4 & 62.9 & 33.7 \\
\hline Calabria & IT & 4.3 & 2.9 & 92.8 \\
\hline Anatoliki Makedonia, Thraki & GR & 9.6 & 41.1 & 49.4 \\
\hline Alentejo & $P$ & 10.7 & 48.1 & 41.2 \\
\hline Voreio Aigaio & GR & 11.5 & 3.8 & 84.7 \\
\hline Canarias & ES & 12.0 & 28.6 & 59.4 \\
\hline London & UK & 13.1 & 21.9 & 65.0 \\
\hline Baleares & ES & 13.6 & 34.2 & 52.3 \\
\hline Ipeiros & GR & 14.6 & 24.3 & 61.0 \\
\hline Kriti & GR & 16.8 & 19.6 & 63.6 \\
\hline Algarve & $P$ & 18.6 & 13.4 & 68.1 \\
\hline Lisboa e Vale do Tejo & $\mathrm{P}$ & 19.2 & 25.0 & 55.8 \\
\hline Notio Aigaio & GR & 20.2 & 0.5 & 79.3 \\
\hline Castilla y León & ES & 20.3 & 59.2 & 20.6 \\
\hline Haute-Normandie & FR & 22.1 & 12.1 & 65.8 \\
\hline Ionia Nisia & GR & 22.4 & 35.0 & 42.6 \\
\hline North East & UK & 22.5 & 47.1 & 30.4 \\
\hline South East & UK & 23.0 & 17.8 & 59.1 \\
\hline Eastern & UK & 23.3 & 23.6 & 53.0 \\
\hline North West (incl.Merseyside) & UK & 23.9 & 69.1 & 7.0 \\
\hline Northern Ireland & UK & 23.9 & 38.0 & 38.1 \\
\hline Yorkshire and The Humber & UK & 24.7 & 50.0 & 25.2 \\
\hline Extremadura & ES & 25.3 & 30.4 & 44.3 \\
\hline Norte & $P$ & 25.4 & 74.6 & 0.0 \\
\hline Wales & UK & 27.5 & 46.7 & 25.9 \\
\hline West Midlands & UK & 28.1 & 66.1 & 5.8 \\
\hline Basilicata & IT & 28.2 & 2.8 & 69.0 \\
\hline Peloponnisos & GR & 29.2 & 51.7 & 19.2 \\
\hline Scotland & UK & 30.9 & 48.5 & 20.6 \\
\hline East Midlands & UK & 31.2 & 57.8 & 11.0 \\
\hline Thessalia & GR & 32.4 & 55.0 & 12.6 \\
\hline Région Bruxelles-capitale & $\mathrm{BE}$ & 32.5 & 29.9 & 37.7 \\
\hline La Rioja & ES & 33.7 & 46.1 & 20.1 \\
\hline Galicia & ES & 33.7 & 32.7 & 33.5 \\
\hline Dytiki Ellada & GR & 34.4 & 44.3 & 21.3 \\
\hline Corse & FR & 34.7 & 30.1 & 35.2 \\
\hline Attiki & GR & 35.6 & 22.4 & 42.0 \\
\hline Languedoc-Roussillon & FR & 36.8 & 21.7 & 41.5 \\
\hline Dytiki Makedonia & GR & 37.1 & 2.3 & 60.6 \\
\hline Sicilia & IT & 37.9 & 46.3 & 15.8 \\
\hline Principado de Asturias & ES & 38.3 & 30.0 & 31.7 \\
\hline Sardegna & IT & 39.0 & 41.8 & 19.3 \\
\hline Murcia & ES & 39.3 & 12.9 & 47.8 \\
\hline Comunidad Foral de Navarra & ES & 39.6 & 16.2 & 44.2 \\
\hline Kentriki Makedonia & GR & 39.6 & 32.9 & 27.5 \\
\hline Cantabria & ES & 40.6 & 35.4 & 24.1 \\
\hline
\end{tabular}


Table 3 (continue) - Ranking of regions according to the variance of GDP European component (\%)

\begin{tabular}{|c|c|c|c|c|}
\hline REGION & COUNTRY & EC & NC & LC \\
\hline West-Nederland & $\mathrm{NL}$ & 43.0 & 18.0 & 39.0 \\
\hline Aragón & ES & 43.2 & 47.7 & 9.2 \\
\hline South West & UK & 44.9 & 46.3 & 8.8 \\
\hline Sterea Ellada & GR & 45.1 & 44.3 & 10.6 \\
\hline Aquitaine & FR & 51.3 & 28.8 & 20.0 \\
\hline Hamburg & $\mathrm{DE}$ & 51.9 & 44.3 & 3.9 \\
\hline Comunidad Valenciana & ES & 52.3 & 17.2 & 30.4 \\
\hline Île de France & FR & 53.0 & 11.0 & 36.0 \\
\hline Pais Vasco & ES & 53.2 & 8.0 & 38.8 \\
\hline Noord-Nederland & $\mathrm{NL}$ & 55.1 & 38.0 & 6.9 \\
\hline Schleswig-Holstein & $\mathrm{DE}$ & 56.2 & 31.1 & 12.6 \\
\hline Région Wallonne & $\mathrm{BE}$ & 57.0 & 27.3 & 15.7 \\
\hline Limousin & FR & 57.2 & 4.3 & 38.5 \\
\hline Auvergne & FR & 58.0 & 10.4 & 31.5 \\
\hline Campania & IT & 58.9 & 6.5 & 34.6 \\
\hline Castilla-la Mancha & ES & 60.6 & 29.5 & 9.8 \\
\hline Basse-Normandie & FR & 62.0 & 15.9 & 22.1 \\
\hline Midi-Pyrénées & FR & 62.4 & 17.5 & 20.1 \\
\hline Andalucia & ES & 62.9 & 19.7 & 17.4 \\
\hline Puglia & IT & 64.2 & 5.3 & 30.5 \\
\hline Franche-Comté & FR & 64.4 & 6.5 & 29.1 \\
\hline Oost-Nederland & $\mathrm{NL}$ & 64.5 & 33.4 & 2.1 \\
\hline Toscana & IT & 66.3 & 8.5 & 25.2 \\
\hline Bourgogne & FR & 67.8 & 16.4 & 15.8 \\
\hline Hessen & $\mathrm{DE}$ & 67.9 & 24.9 & 7.2 \\
\hline Lazio & IT & 68.8 & 19.9 & 11.3 \\
\hline Comunidad de Madrid & ES & 69.0 & 18.2 & 12.8 \\
\hline Niedersachsen & $\mathrm{DE}$ & 69.2 & 29.2 & 1.6 \\
\hline Alsace & FR & 69.4 & 4.6 & 26.0 \\
\hline Vlaams Gewest & $\mathrm{BE}$ & 69.9 & 27.1 & 3.0 \\
\hline
\end{tabular}


Table 3 (continue) - Ranking of regions according to the variance of GDP European component (\%)

\begin{tabular}{lcccc} 
High-integrated & \multicolumn{3}{c}{} \\
\hline REGION & COUNTRY & EC & NC & LC \\
\hline Poitou-Charentes & FR & 70.1 & 8.2 & 21.7 \\
Zuid-Nederland & NL & 70.4 & 28.3 & 1.3 \\
Bretagne & FR & 70.5 & 29.5 & 0.0 \\
Cataluña & ES & 70.9 & 25.7 & 3.4 \\
Centre & FR & 71.3 & 11.7 & 17.0 \\
Saarland & DE & 71.4 & 15.6 & 13.0 \\
Umbria & IT & 72.2 & 6.7 & 21.1 \\
Trentino-Alto Adige & IT & 75.1 & 5.4 & 19.5 \\
Valle d"Aosta & IT & 75.2 & 6.8 & 18.0 \\
Pays de la Loire & FR & 75.5 & 6.8 & 17.7 \\
Rheinland-Pfalz & DE & 75.5 & 18.1 & 6.4 \\
Marche & IT & 75.6 & 7.8 & 16.6 \\
Bayern & DE & 76.5 & 21.7 & 1.8 \\
Provence-Alpes-Côte d"Azur & FR & 77.3 & 6.7 & 16.1 \\
Molise & IT & 78.4 & 6.9 & 14.6 \\
Emilia-Romagna & IT & 78.9 & 10.5 & 10.6 \\
Bremen & DE & 79.7 & 7.8 & 12.5 \\
Picardie & FR & 79.8 & 2.4 & 17.9 \\
Nordrhein-Westfalen & DE & 80.7 & 17.3 & 2.0 \\
Liguria & IT & 81.3 & 6.3 & 12.4 \\
Champagne-Ardenne & FR & 82.5 & 1.2 & 16.2 \\
Nord - Pas-de-Calais & FR & 82.6 & 2.0 & 15.4 \\
Veneto & IT & 83.3 & 7.2 & 9.6 \\
Baden-Württemberg & DE & 84.5 & 14.5 & 1.0 \\
Lombardia & IT & 85.3 & 8.8 & 5.8 \\
Lorraine & FR & 86.0 & 0.5 & 13.4 \\
Rhône-Alpes & FR & 86.6 & 7.0 & 6.4 \\
Piemonte & IT & 86.8 & 6.2 & 7.0 \\
Friuli-Venezia Giulia & 87.8 & 9.5 & 2.7 \\
Abruzzo & 87.9 & 8.0 & 4.1 \\
\hline
\end{tabular}




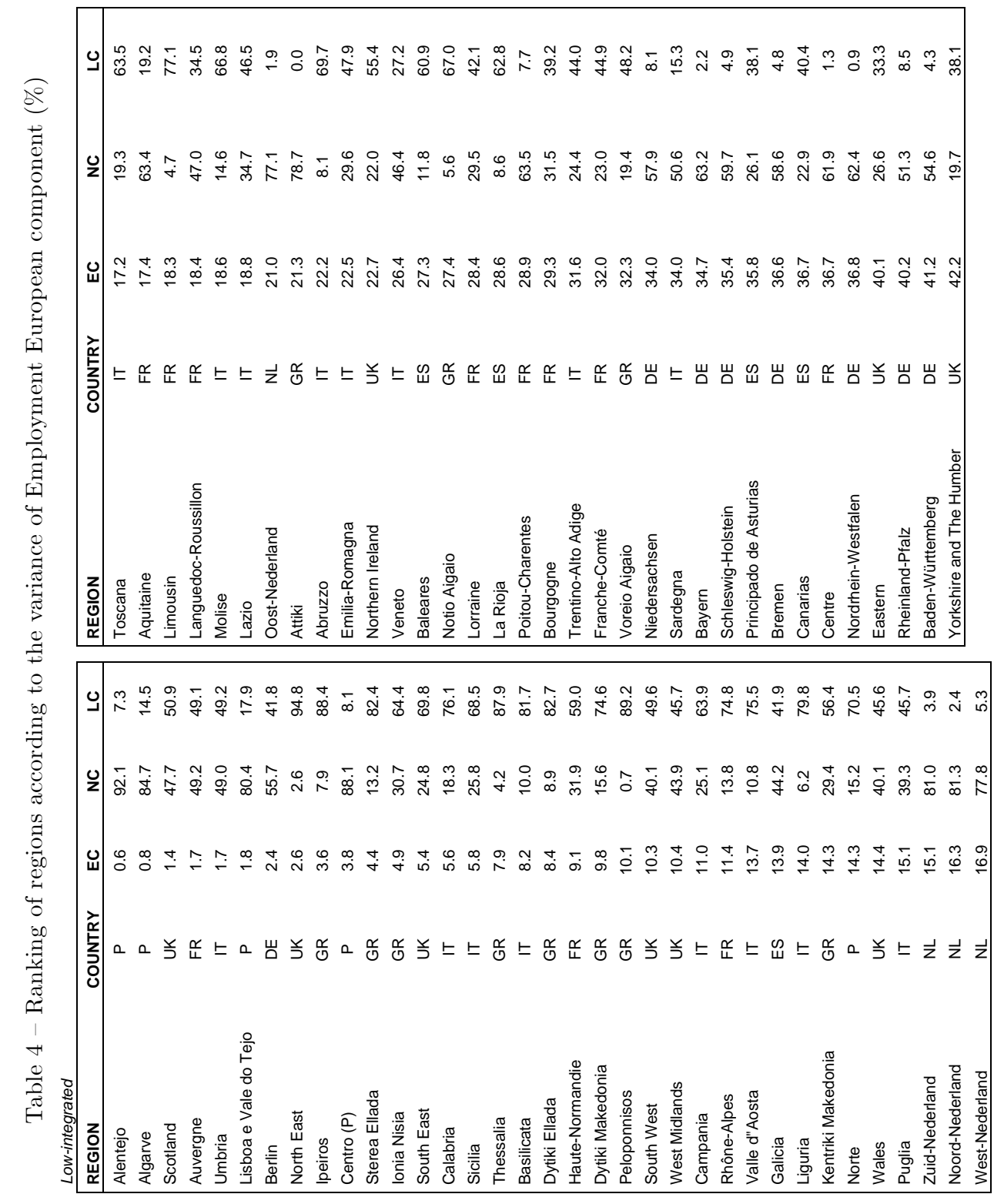


Table 4 (continue) - Ranking of regions according to the variance of Employment European component (\%)

\begin{tabular}{|c|c|c|c|c|}
\hline REGION & COUNTRY & EC & NC & LC \\
\hline Castilla-la Mancha & ES & 43.5 & 31.4 & 25.1 \\
\hline Comunidad de Madrid & ES & 43.8 & 28.2 & 27.9 \\
\hline Anatoliki Makedonia, Thraki & GR & 44.0 & 31.0 & 25.0 \\
\hline Pays de la Loire & $\mathrm{FR}$ & 45.7 & 5.4 & 49.0 \\
\hline Hessen & $\mathrm{DE}$ & 45.7 & 53.3 & 1.0 \\
\hline Pais Vasco & ES & 46.2 & 19.9 & 33.9 \\
\hline East Midlands & UK & 47.0 & 44.0 & 9.1 \\
\hline Basse-Normandie & $\mathrm{FR}$ & 47.0 & 0.8 & 52.2 \\
\hline Piemonte & IT & 47.8 & 18.0 & 34.2 \\
\hline Extremadura & ES & 48.1 & 38.5 & 13.4 \\
\hline Castilla y León & ES & 49.0 & 43.7 & 7.3 \\
\hline Picardie & $\mathrm{FR}$ & 49.1 & 25.6 & 25.2 \\
\hline Île de France & $\mathrm{FR}$ & 49.2 & 5.8 & 45.0 \\
\hline Bretagne & $\mathrm{FR}$ & 50.3 & 1.2 & 48.5 \\
\hline Friuli-Venezia Giulia & IT & 50.6 & 21.7 & 27.7 \\
\hline Corse & $\mathrm{FR}$ & 50.9 & 7.9 & 41.2 \\
\hline Provence-Alpes-Côte d'Azur & $\mathrm{FR}$ & 51.1 & 1.9 & 46.9 \\
\hline Marche & IT & 51.3 & 14.4 & 34.3 \\
\hline Alsace & FR & 52.6 & 1.8 & 45.5 \\
\hline Midi-Pyrénées & $\mathrm{FR}$ & 52.7 & 4.6 & 42.7 \\
\hline Murcia & ES & 53.1 & 18.7 & 28.2 \\
\hline Aragón & ES & 54.9 & 34.9 & 10.2 \\
\hline Hamburg & DE & 56.6 & 38.7 & 4.7 \\
\hline Cantabria & ES & 56.9 & 17.4 & 25.7 \\
\hline Nord - Pas-de-Calais & $\mathrm{FR}$ & 57.1 & 0.1 & 42.9 \\
\hline Champagne-Ardenne & $\mathrm{FR}$ & 57.3 & 4.1 & 38.6 \\
\hline Kriti & GR & 57.7 & 14.0 & 28.2 \\
\hline Comunidad Valenciana & ES & 59.6 & 25.8 & 14.7 \\
\hline Région Bruxelles-capitale & BE & 60.3 & 15.0 & 24.7 \\
\hline Comunidad Foral de Navarra & ES & 61.2 & 25.0 & 13.8 \\
\hline North West (incl.Merseyside) & UK & 61.9 & 7.6 & 30.5 \\
\hline Andalucia & ES & 62.3 & 34.0 & 3.8 \\
\hline Région Wallonne & $\mathrm{BE}$ & 65.5 & 24.2 & 10.3 \\
\hline Cataluña & ES & 65.9 & 22.6 & 11.5 \\
\hline \multicolumn{5}{|l|}{ High-integrated } \\
\hline REGION & COUNTRY & EC & $\mathrm{NC}$ & LC \\
\hline Lombardia & IT & 71.2 & 19.8 & 9.0 \\
\hline Saarland & $\mathrm{DE}$ & 73.0 & 2.3 & 24.7 \\
\hline Vlaams Gewest & $\mathrm{BE}$ & 80.3 & 18.1 & 1.6 \\
\hline London & UK & 91.8 & 8.1 & 0.1 \\
\hline
\end{tabular}




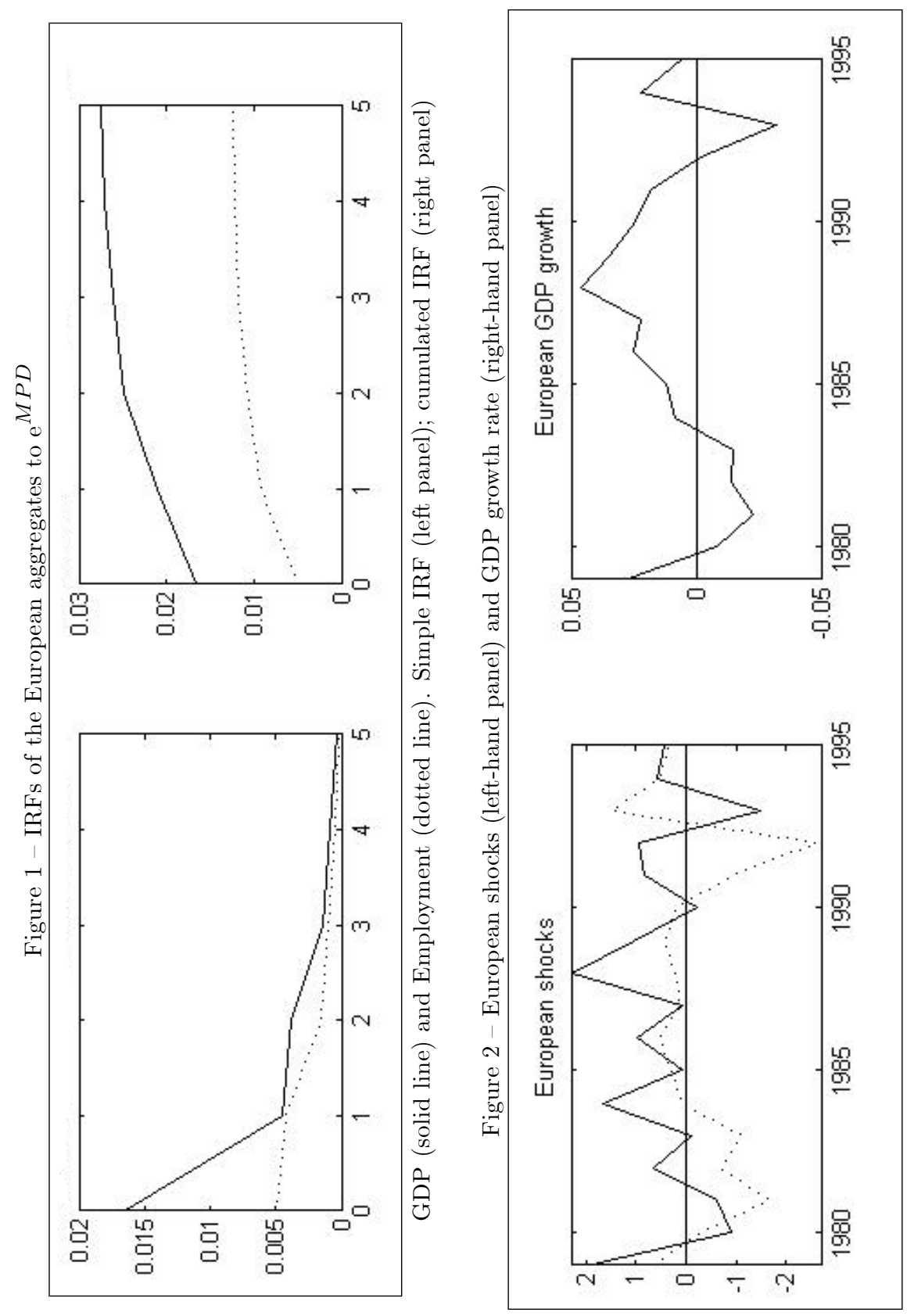




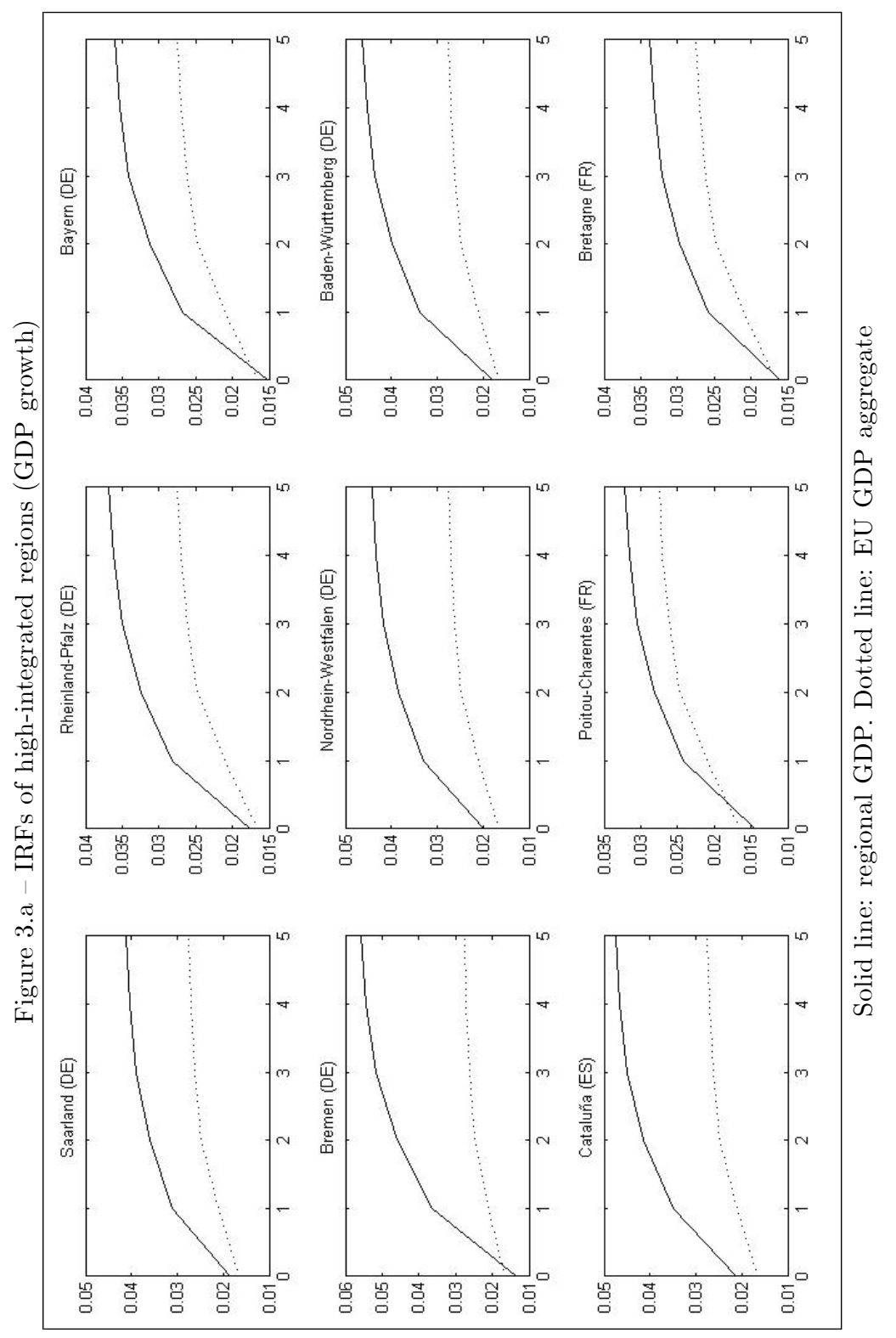




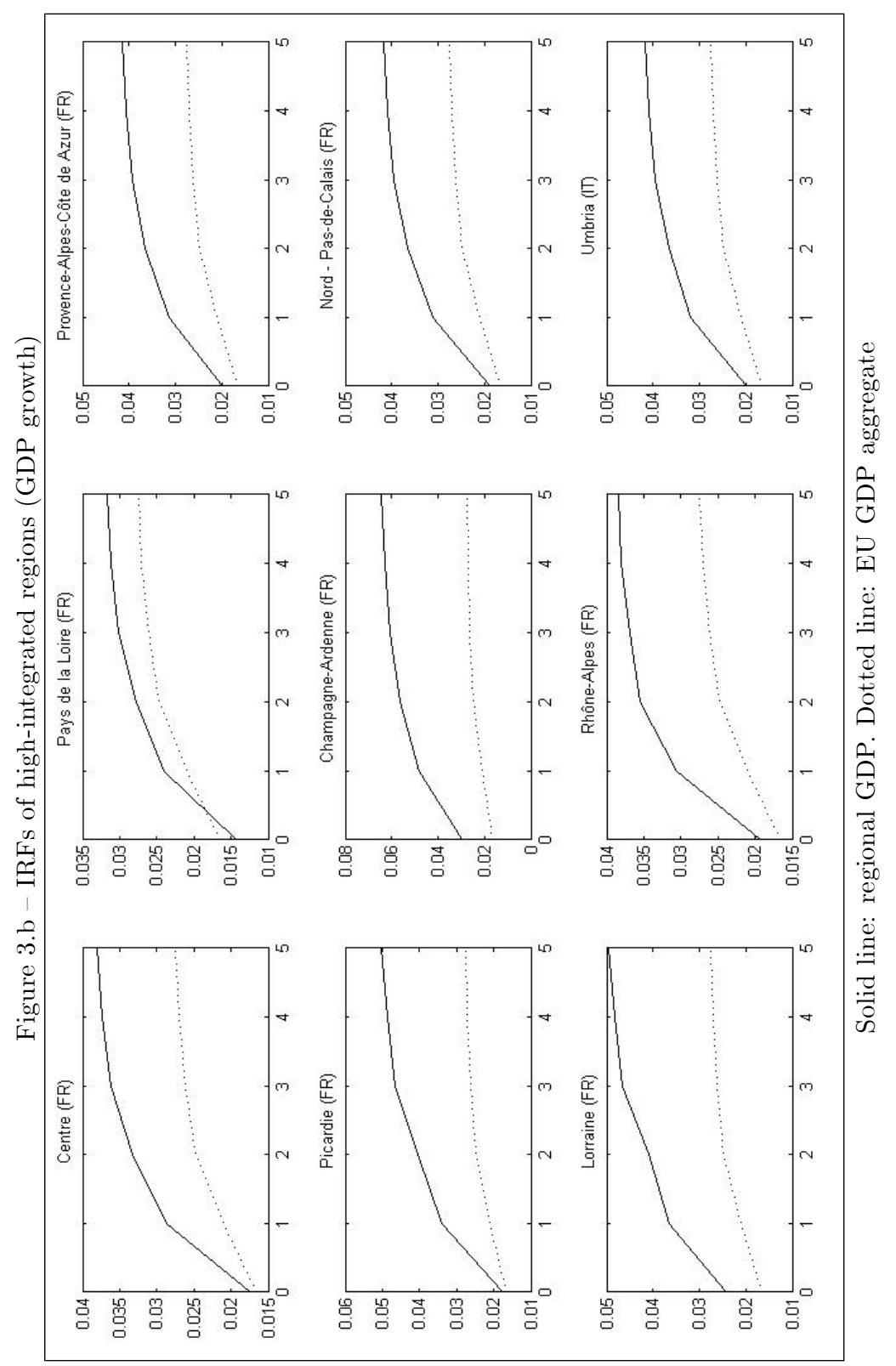




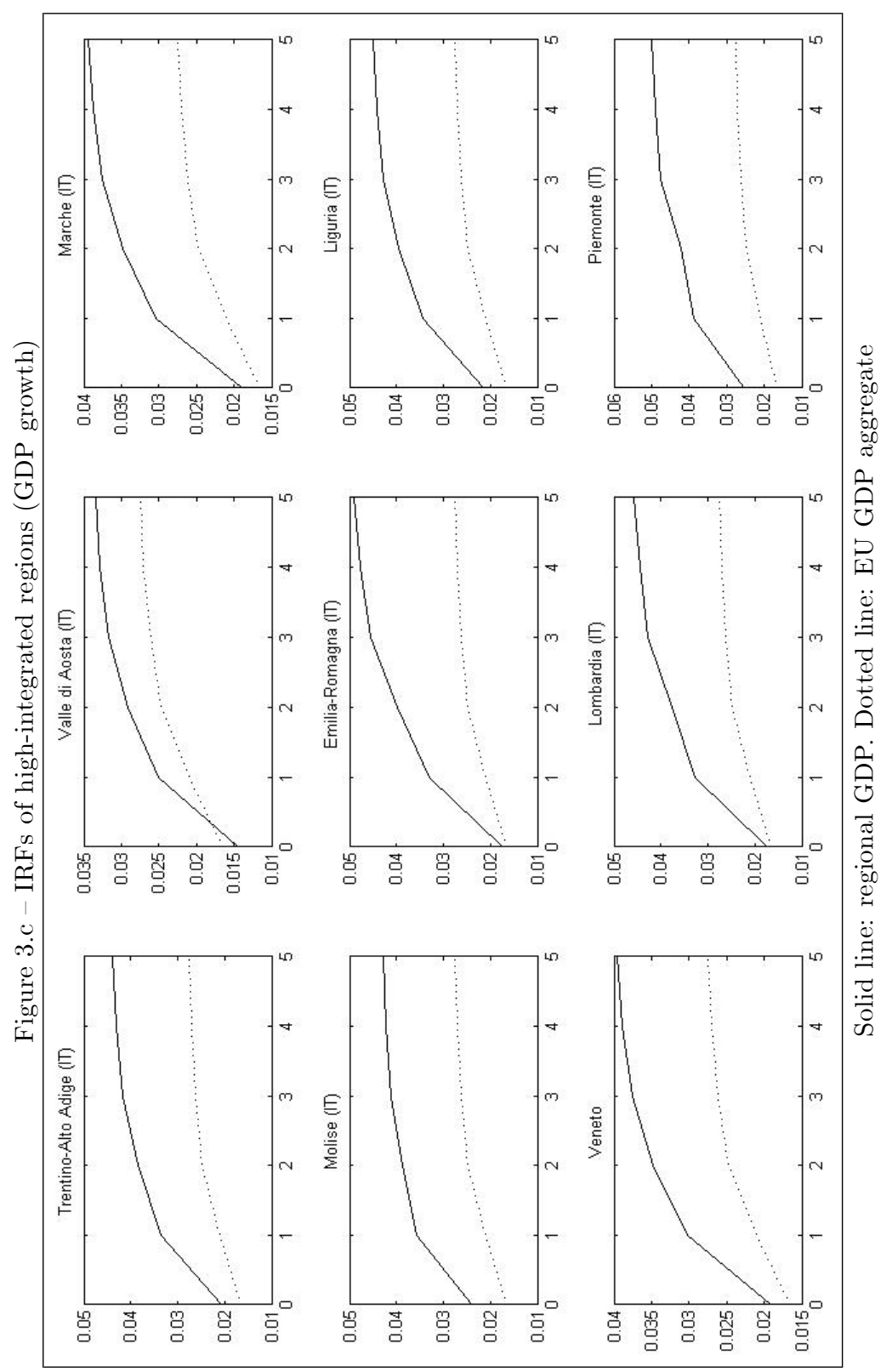




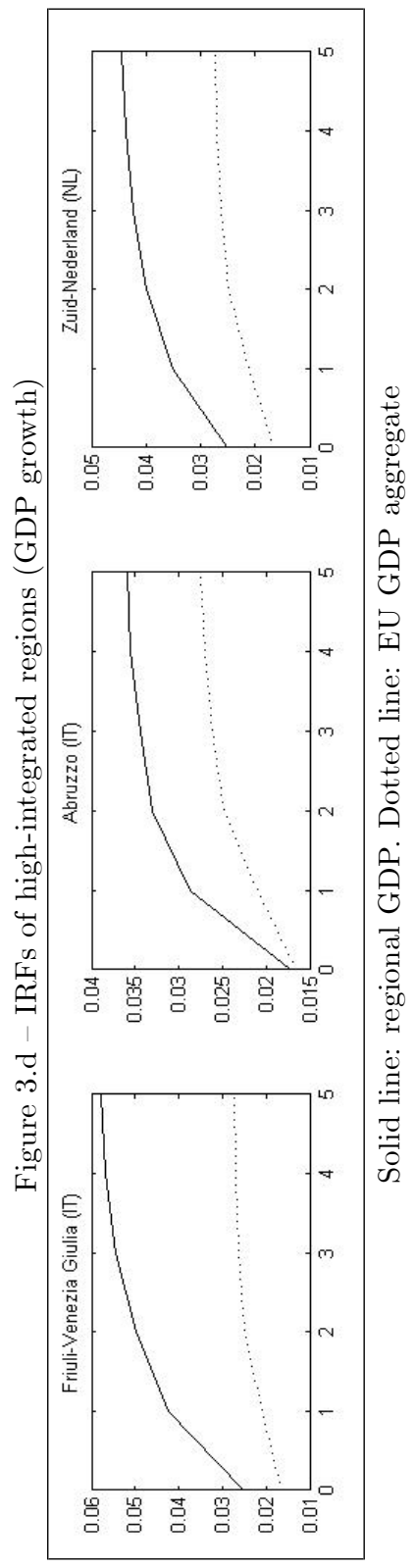




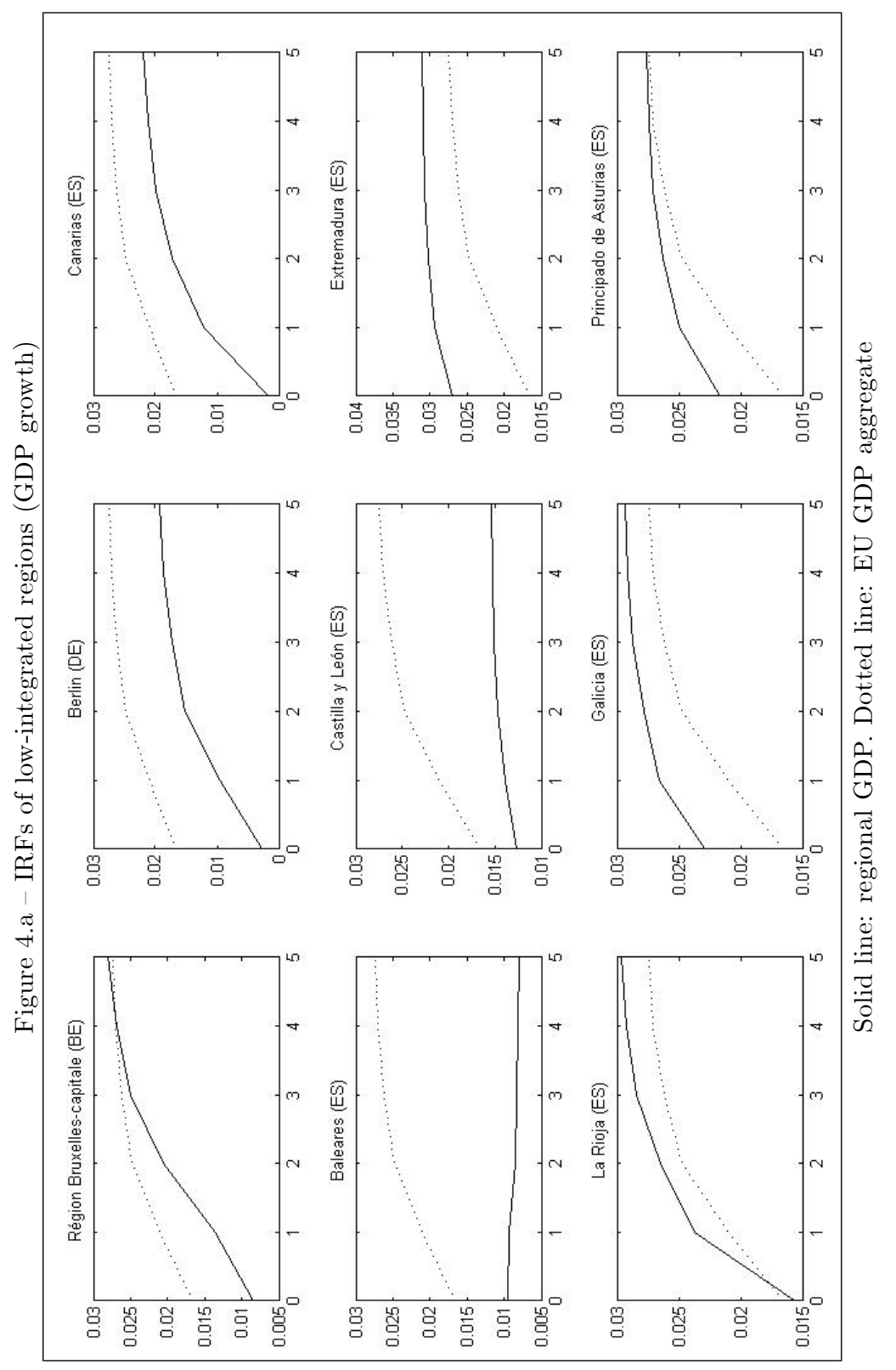




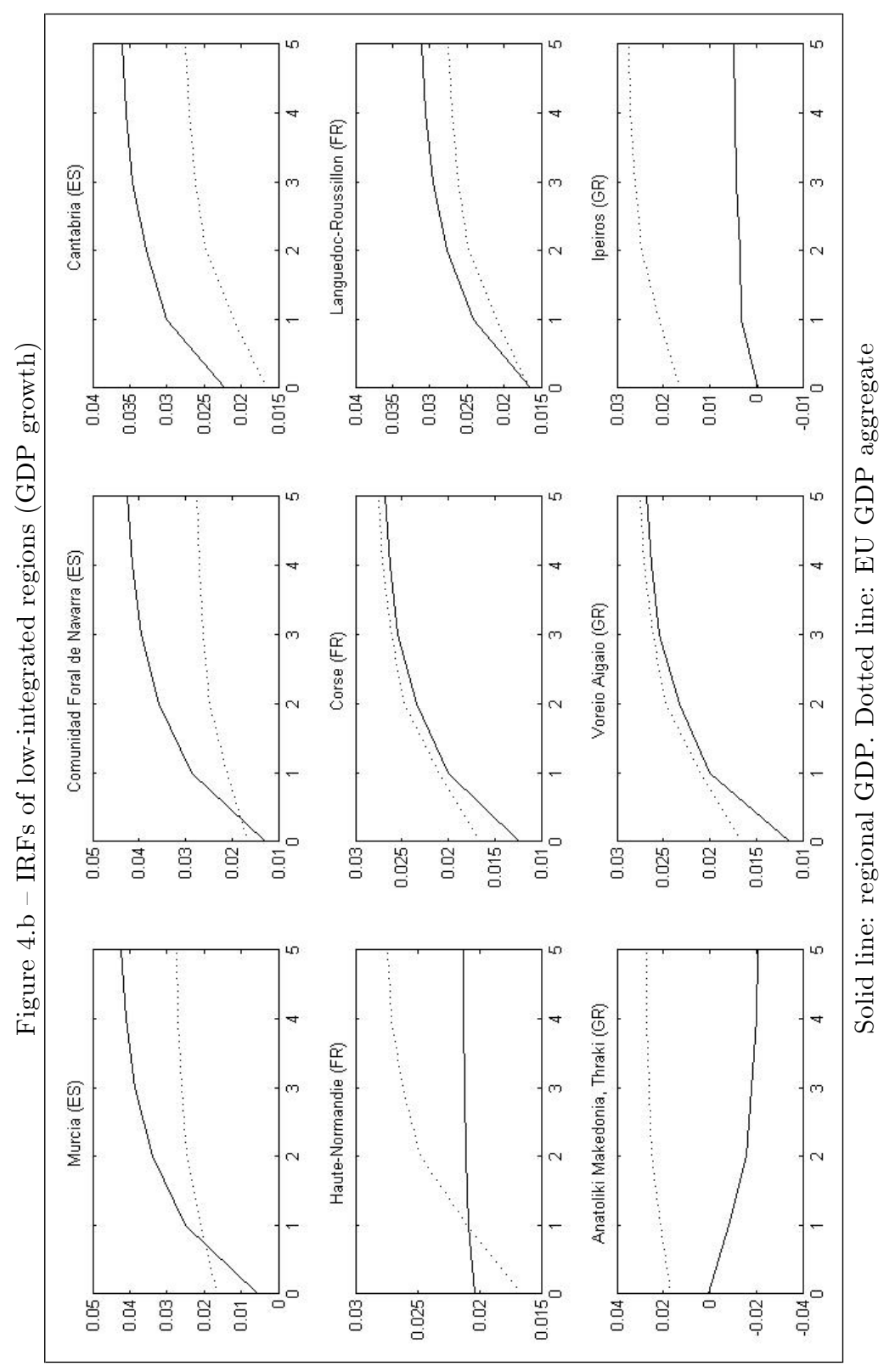




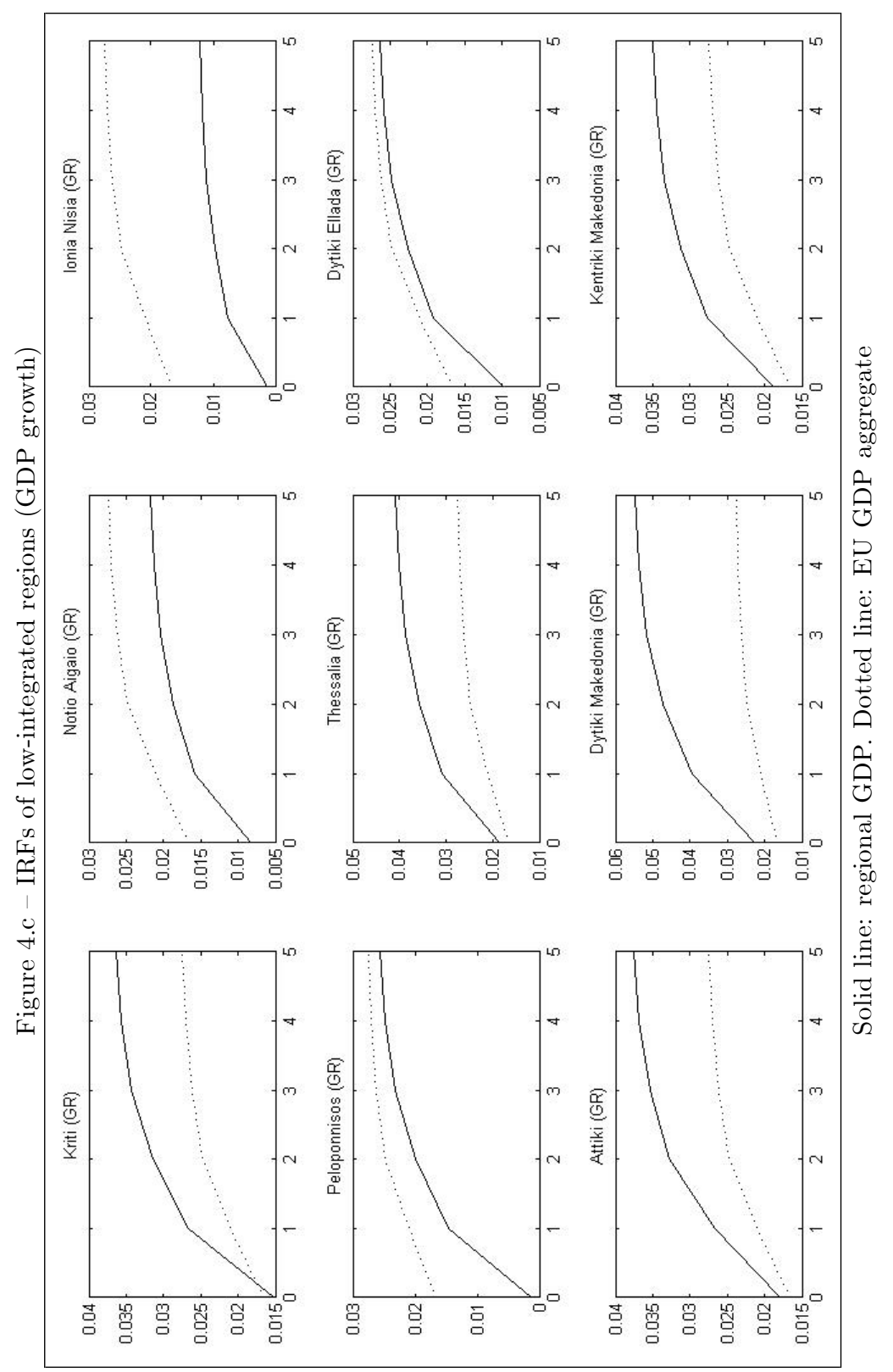




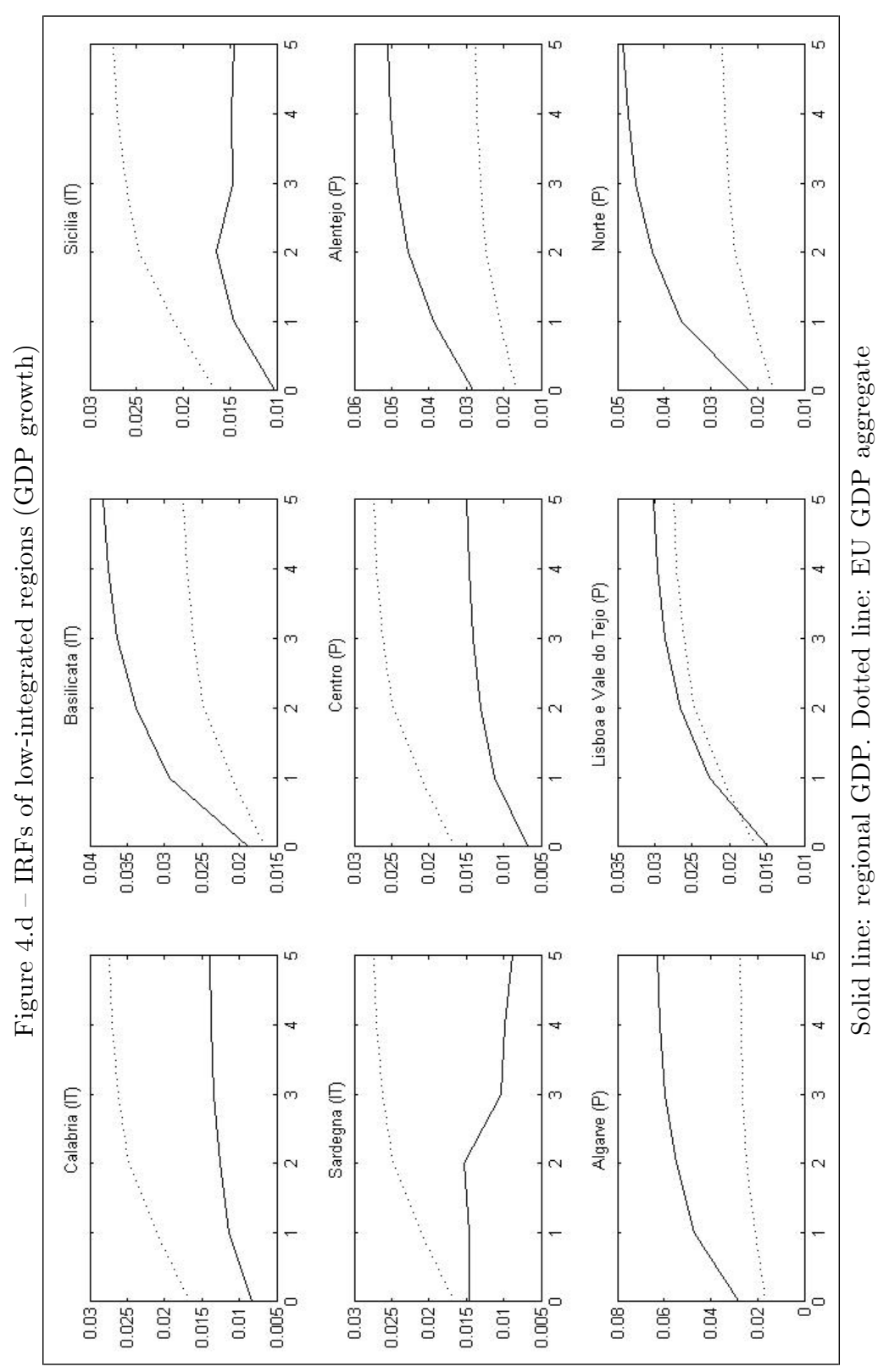




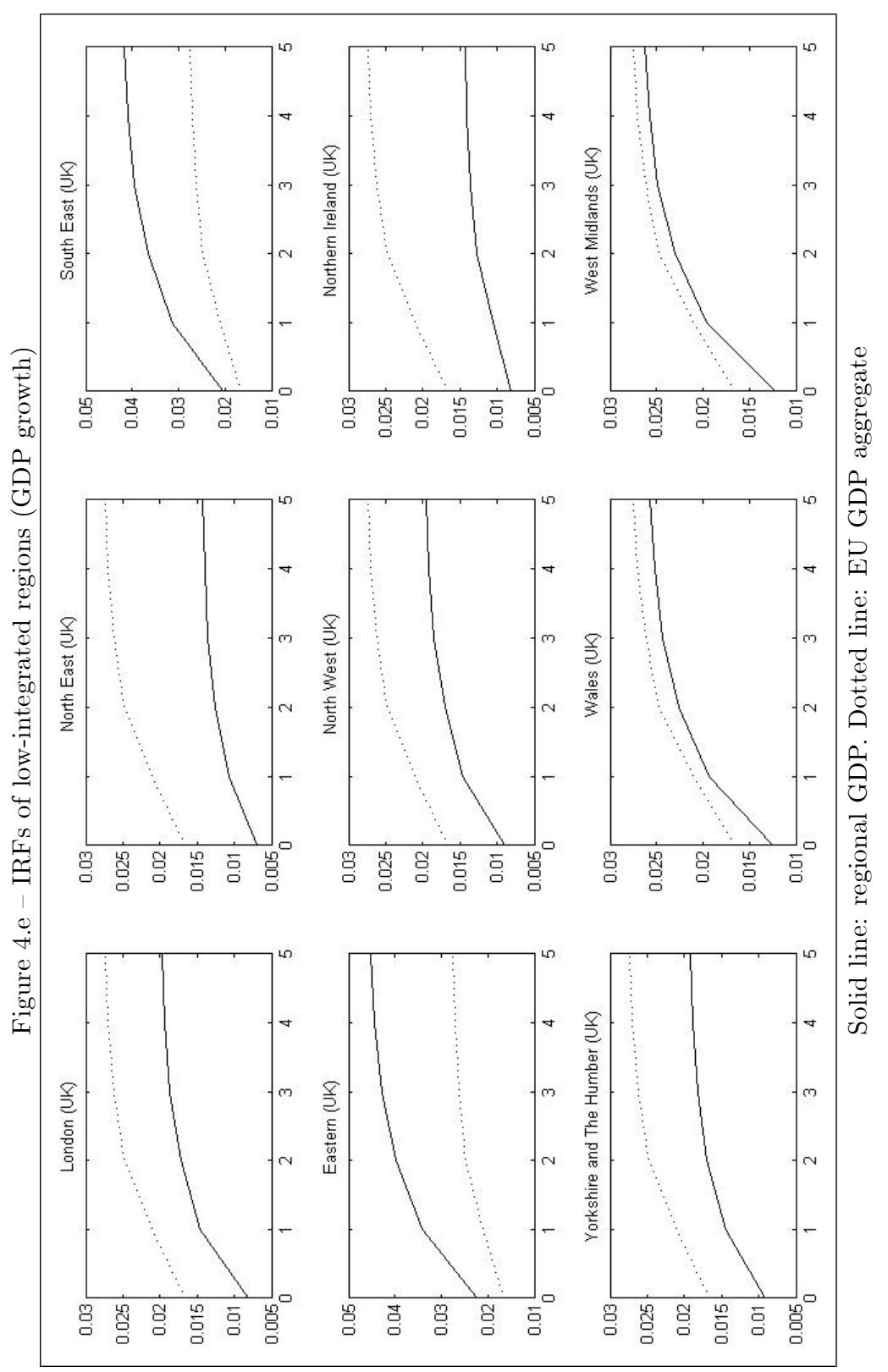




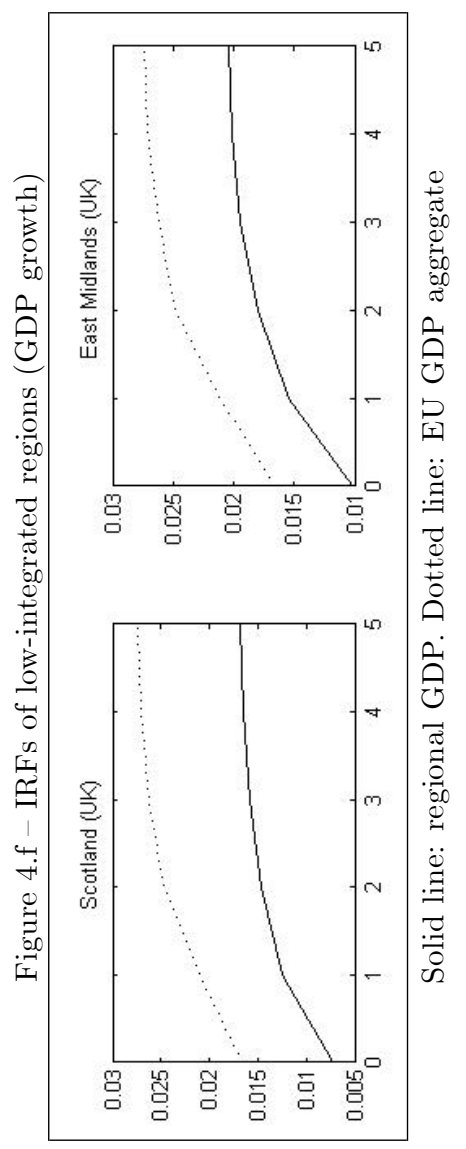




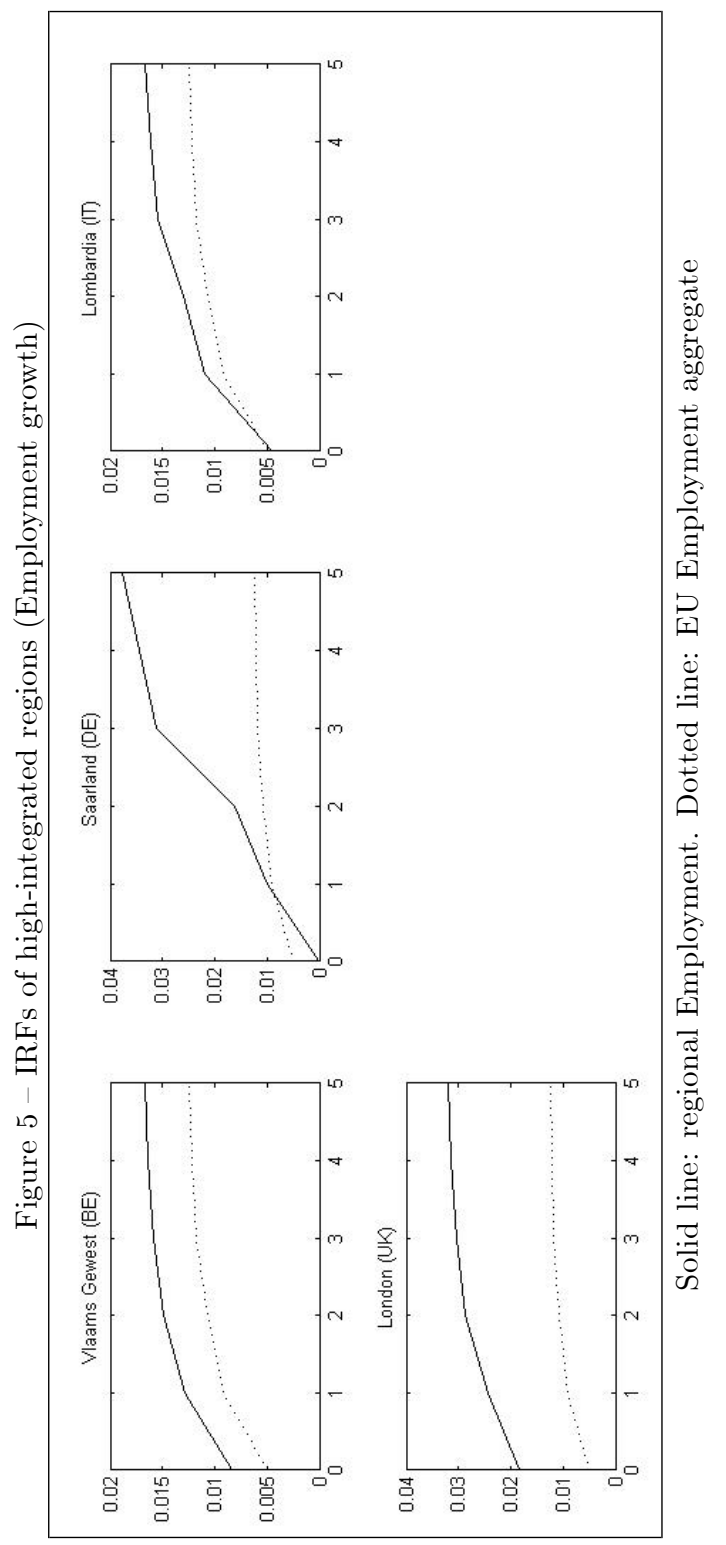




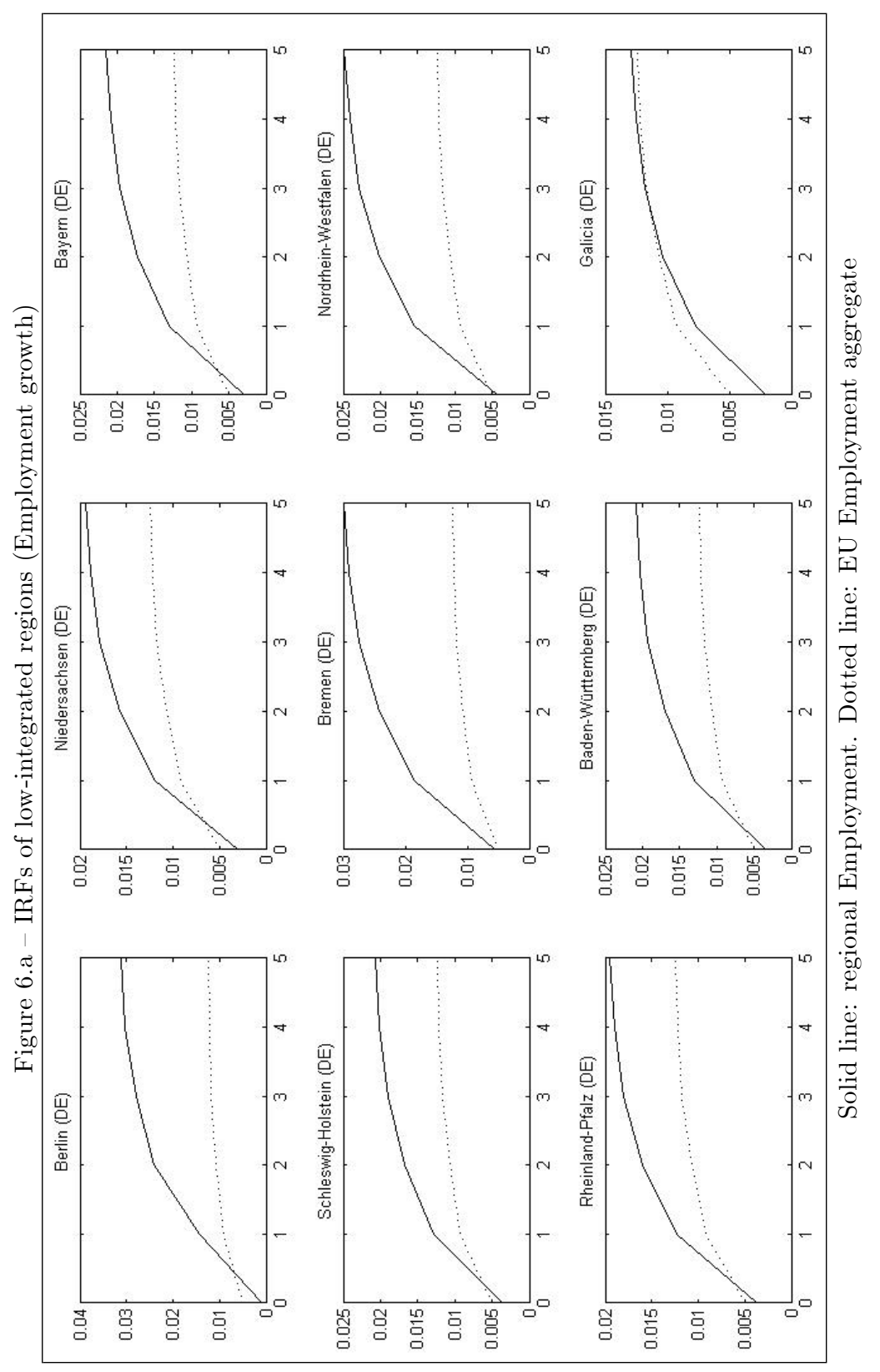




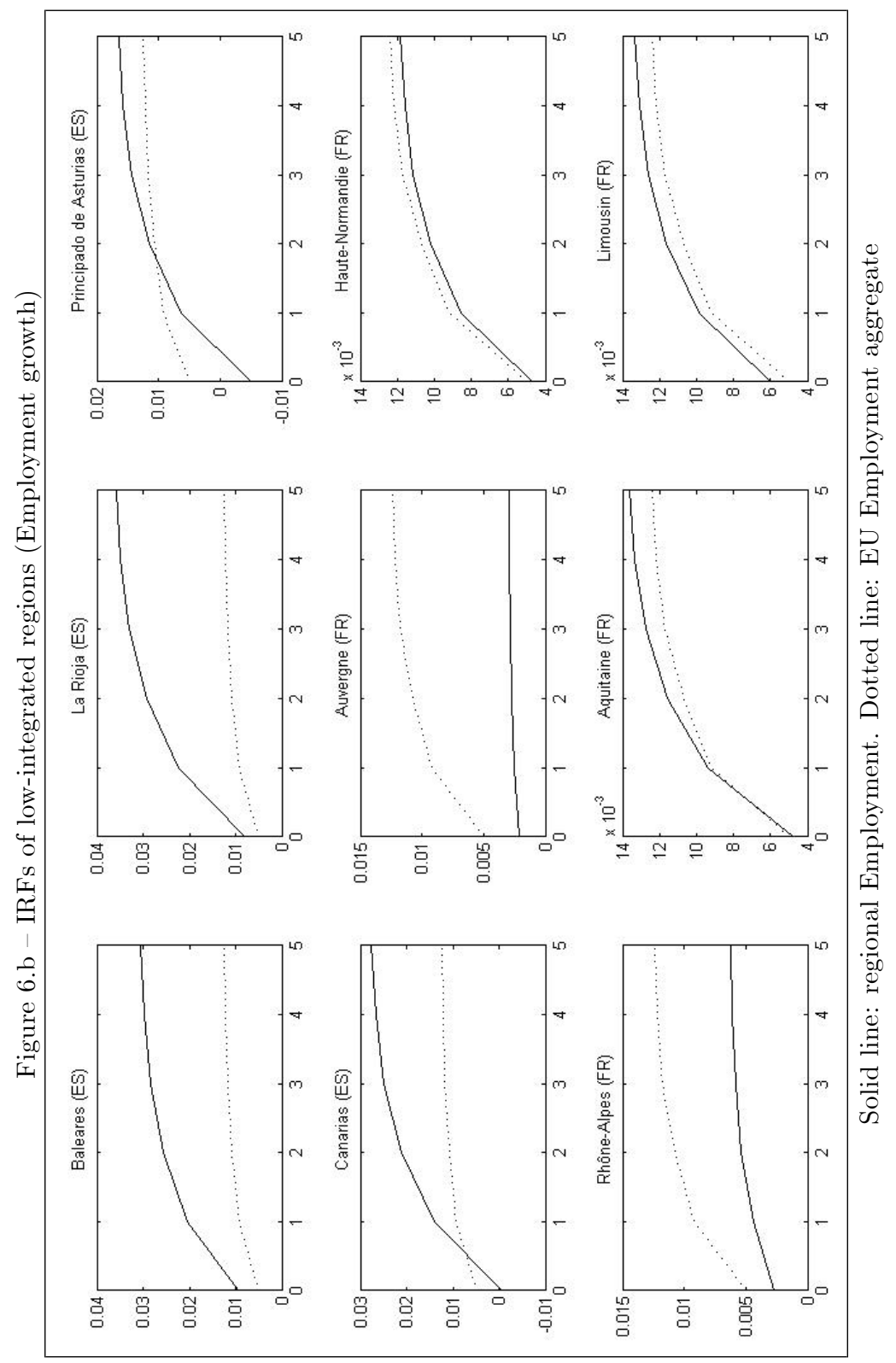




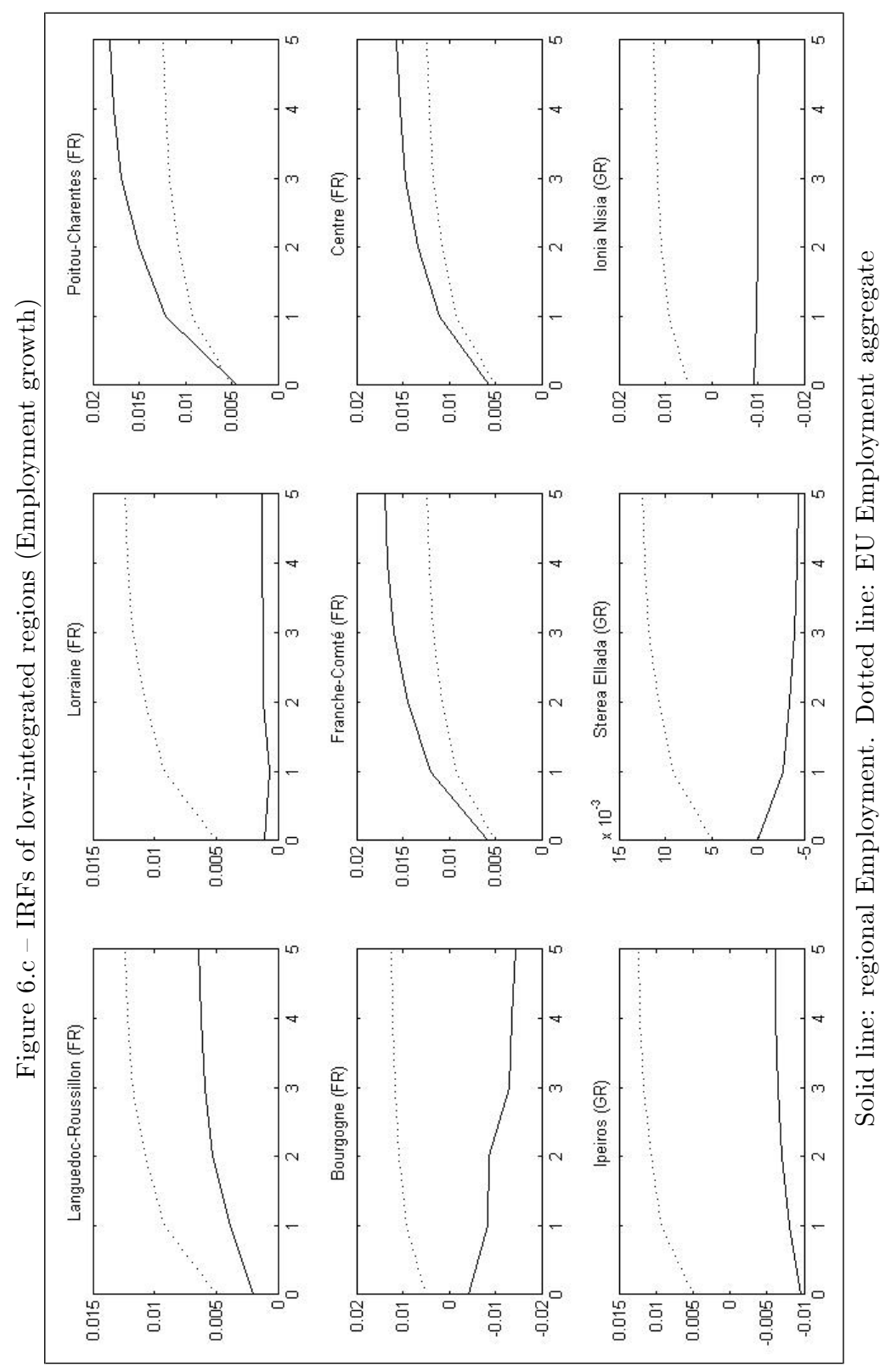




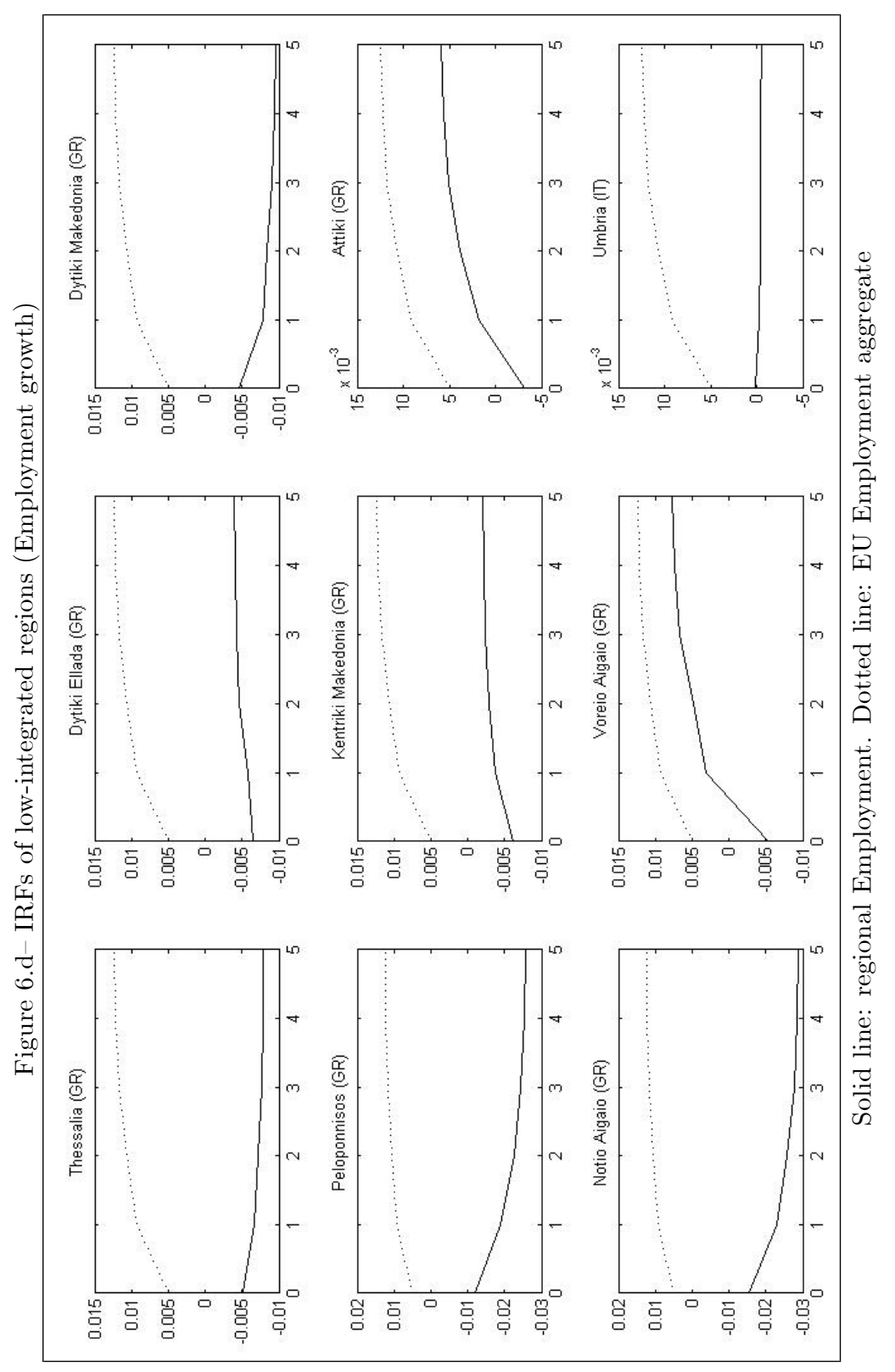




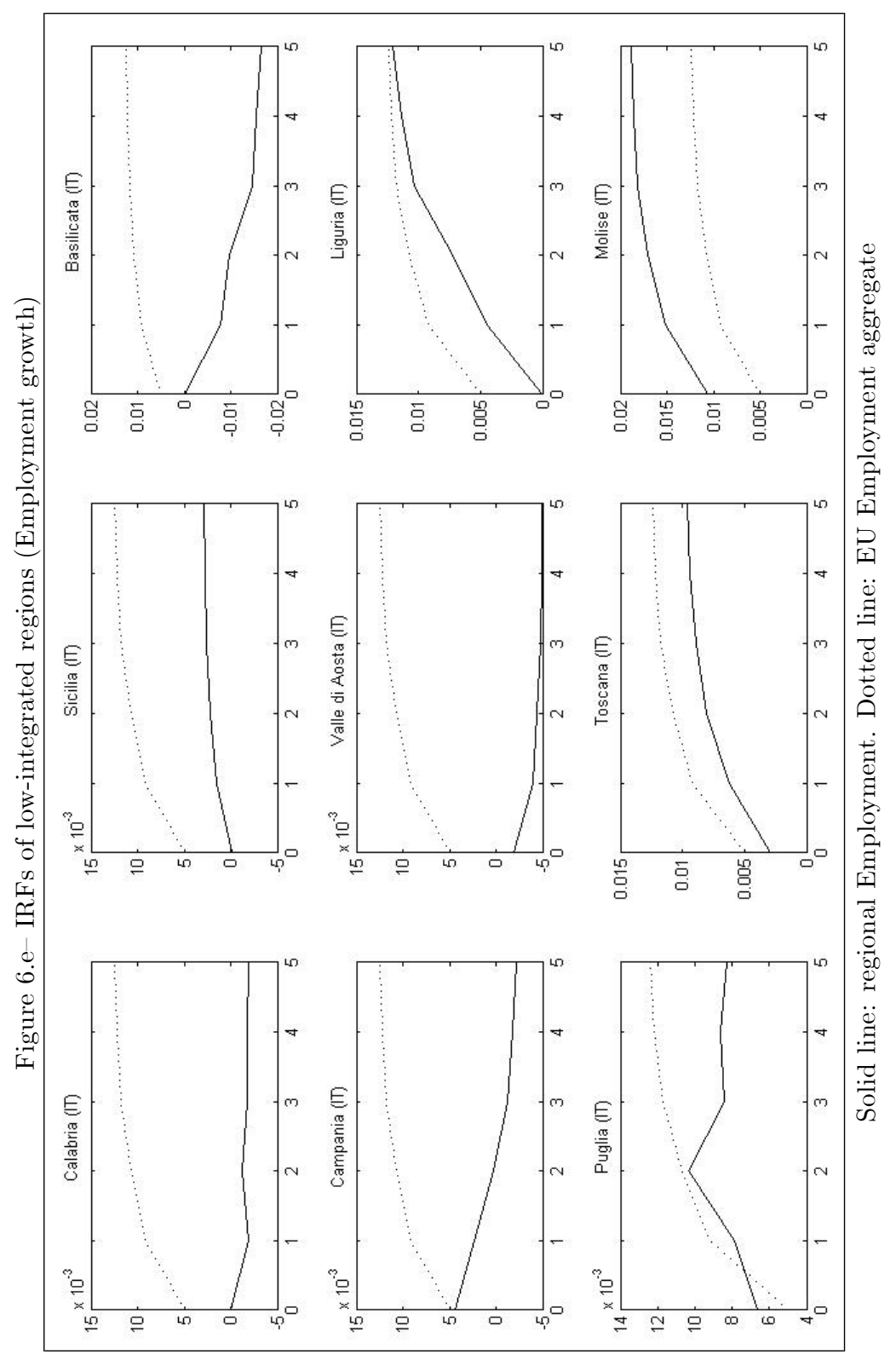




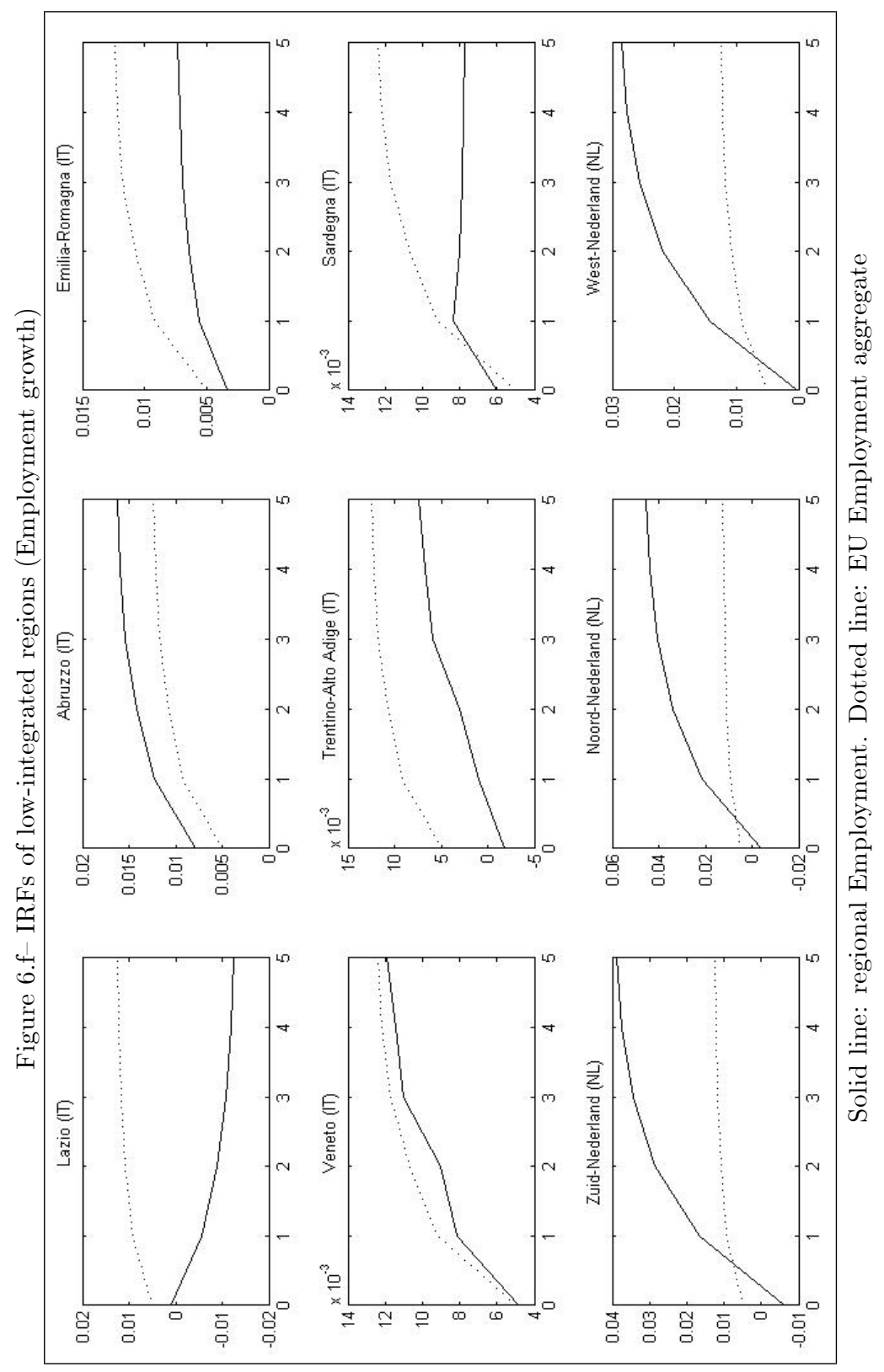




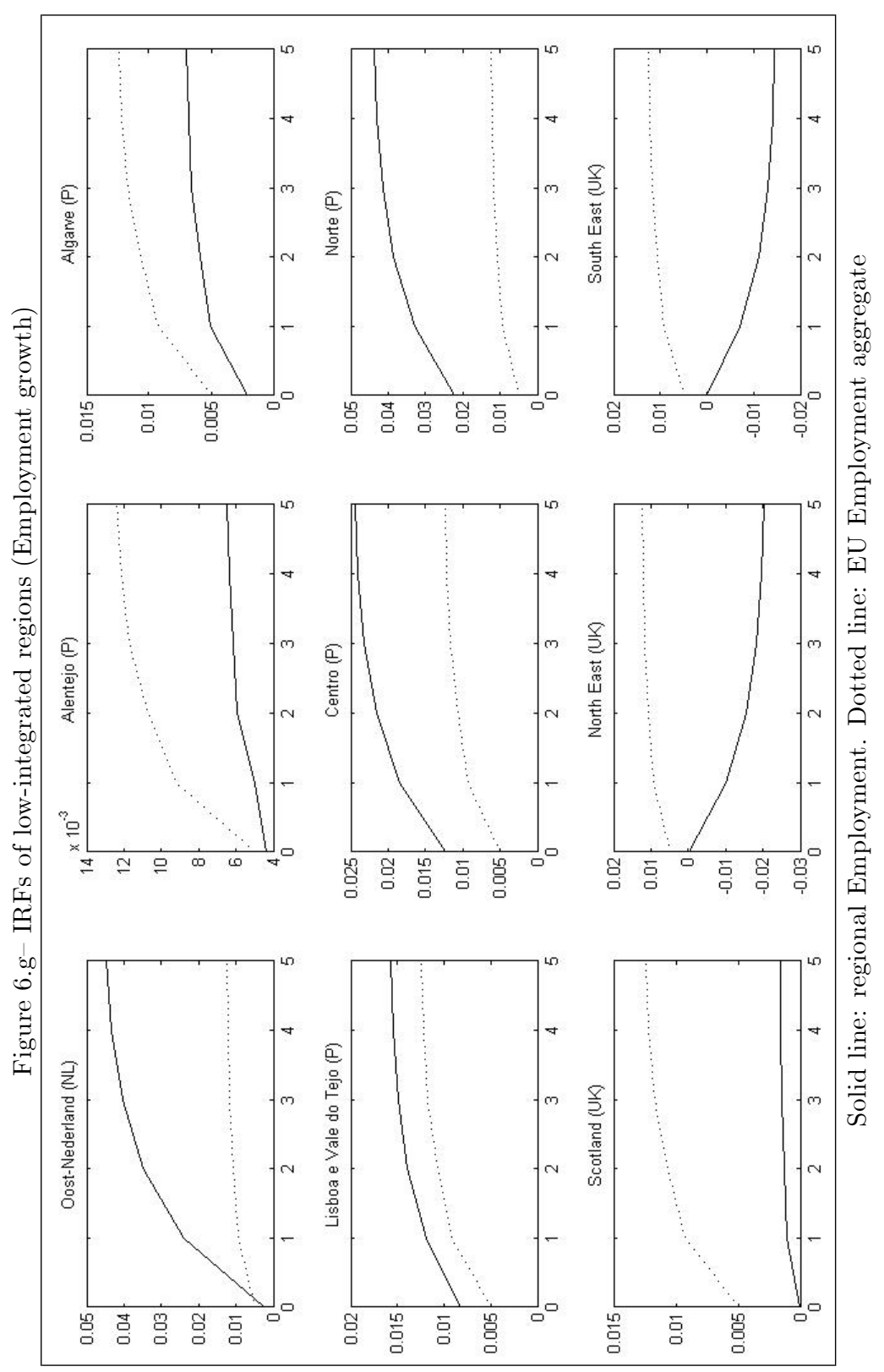




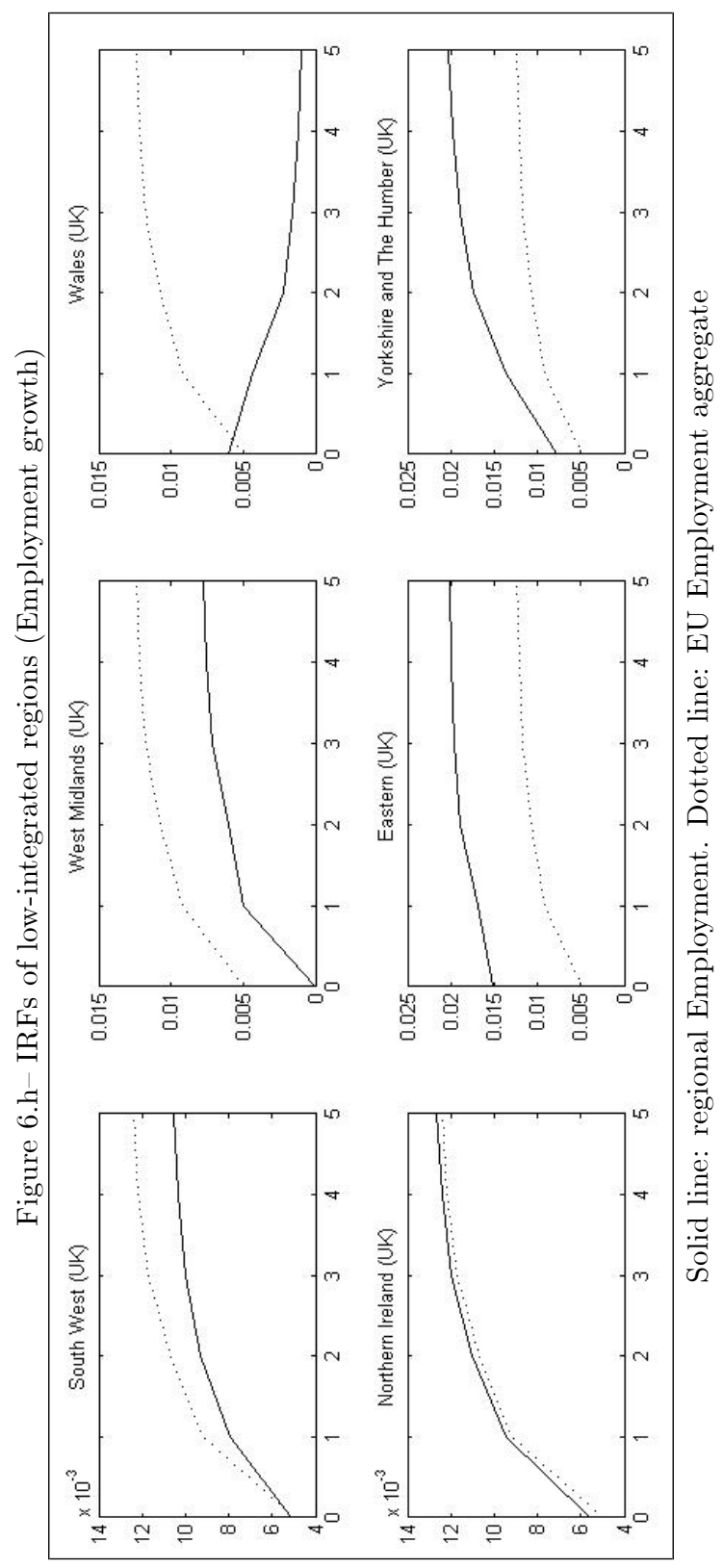

